\title{
Experimental investigation and a novel direct strength method for cold-formed built-up I-section columns
}

\author{
Yan $\mathrm{Lu}^{\mathrm{a}}$ *, Tianhua Zhou ${ }^{\mathrm{a}}$, Wenchao $\mathrm{Li}^{\mathrm{a}}$, Hanheng $\mathrm{Wu}^{\mathrm{a}}$ \\ ${ }^{a}$ School of Civil Engineering, Chang'an University,Xi'an 710061,China
}

\author{
*Corresponding Author: Dr. Yan Lu \\ School of Civil Engineering \\ Chang'an University, Xi'an, Shaanxi Province 710061, China \\ Telephone: +8615829085128 \\ E-mail: luyan@chd.edu.cn
}

\begin{abstract}
This paper aims at investigating the structural response and predicting the ultimate strength of the cold-formed built-up I-section columns affected by local, distortional, global and in particular by the local-distortional (LD) interactive and local-distortional-global (LDG) interactive buckling modes. For this purpose, a total of 18 single C-section columns and 18 built-up I-section columns were tested under uniaxial compression load, respectively. The cross-sectional dimension, the thickness and the length of the tested members were varied in the test so as to cover a wide range of local, distortional and overall slenderness. It
\end{abstract} was shown in the test that noticeable LD interaction was observed for a built-up column with short length as well as LDG interaction for a built-up column with intermediate length. Due to the clear evidence obtained in the test that LD and LDG interactions cause substantial ultimate strength erosion in cold-formed built-up I-section column, a novel direct strength based method was proposed in this paper to quantify such an erosion effect. The validity of the proposed method was then verified by comparing the results obtained from the proposed method with the test results in this paper as well as several other test results in the literature. The comparison results proved that the proposed method can be used successfully in estimating the ultimate strength of cold-formed built-up I-section column affected by pure buckling mode as well as interactive 
buckling mode.

Keywords: Cold-formed steel; Built-up I-section column; Experimental investigation; Direct strength method; Local-distortional interaction; Local-distortional-global interaction.

\section{Introduction}

Advances in technology and low production costs have prompted the Cold-Formed Steel (CFS) industry to search for more structurally efficient cross-section shapes. One of the most favorable ways to perform this task is to connect two or more single members together to form a built-up section, e.g. simply connecting two channel sections back to back to form a built-up I-section or in flanges to form a built-up box section. As a result, such a member with built-up sections can be utilized to carry more load and span more distance.

Currently, two basic design methods for cold-formed steel members are formally available in design specifications in North America [1], namely the effective width method (EWM) and the direct strength method (DSM). However, only the effective width method is formally available for cold-formed built-up members, which specifies the modified slenderness ratio to take the effect of shear force into account, as is shown in Eq.1:

$$
\left(\frac{K L}{r}\right)_{m}=\sqrt{\left(\frac{K L}{r}\right)_{0}^{2}+\left(\frac{a}{r_{i}}\right)^{2}}
$$

where $(K L / r)_{\mathrm{o}}$ is the overall slenderness ratio of the entire section with respect to the built-up member axis; $a$ is the fasteners spacing; $r_{\mathrm{i}}$ is the minimum radius of gyration of the full unreduced cross-sectional area of an individual shape in a built-up member.

The modified slenderness ratio is based on the researches of hot rolled built-up members [2,3], which is mainly focused on the detrimental effect of global buckling. However, since the cold-formed members are often controlled by local buckling and distortional buckling [4], it seems to be inappropriate to directly extend this method to determine the ultimate strength of cold-formed members failing in local (L), distortional (D) and other forms of cross-section distortions. For this purpose, Stone and Laboube [5] had experimentally investigated the buckling behavior of built up I-section columns formed by self-drilling screws. Their study provided experimental evidence that the modified slenderness method would result in excessively conservative estimates for the built-up column with intermediate length $(2.1 \mathrm{~m})$. Similarly, such a 
phenomenon was also observed by Whittle and Ramseyer [6] for CFS built-up box-section column formed by welding.

More recently, $\mathrm{Li}$ and $\mathrm{Li}$ [7] had experimentally and numerically studied the ultimate strength of CFS box-section columns and proposed a feasible way to determine the ultimate strength of these members. In addition, the buckling behavior of the built-up I-section columns was also studied in their study by means of the numerical method. Zhang and Young had experimentally [8] and numerically [9] studied the ultimate strength of CFS built-up I-section columns with edge and web stiffeners and evaluated the appropriateness of the direct strength method for built-up open section compressed members. Moreover, it is worth to mention that the buckling behavior of the cold-formed built-up beams has also been investigated in some researches, such as $\mathrm{Li}$ and $\mathrm{Li}[10]$ and Wang and Young [11].

According to above literature review, it can be clearly seen that some researches concerning the ultimate capacity strength of CFS built-up columns have been conducted in the past decades. However, there are still some points worth to be mentioned, which can be summarized as follows:

(1) Firstly, the research concerning the structural behavior of CFS built-up I-section column is still limited. The available experimental investigation [4] mainly focused on the behavior of the CFS built-up I-section columns with intermediate length. Indeed, the intermediately long cold-formed members are often controlled by local-global interactions, which, however, is difficult to be used to study the basic structural behavior of columns affected by pure buckling modes (i.e., local, distortional and global buckling). Therefore, additional experiments are still required to compensate the lack of information on these pure buckling modes.

(2) Currently, extensive studies have been conducted on the structural response of individual C-section cold-formed members affected by LD [12 15] and LDG [16, 17] interactions and have proved that the occurrence of LD and LDG interactions result in a substantial strength erosion. However, according to the authors' knowledge, there seems no research concerning the structural behavior of the built-up I-section columns affected by LD and LDG interactive failure modes. Therefore, additional researches on such a problem are still required.

In this complex scenario, this paper aims to investigate the structural response of the cold-formed 
built-up I-section columns affected by pure and interactive buckling mode and propose a novel direct strength method for cold-formed built-up I-section columns. For this purpose, a series single C-section columns and built-up I-section columns, which contain two cross-section type and three length type (i.e., stub column, intermediate length column and long column), were tested under uniaxial compression load in this paper. In the test, clear evidence was obtained that LD and LDG interactions cause substantial strength erosion in cold-formed I-section column. Then, based on the test result as well as other test results from the literature [18], a DSM-based method was proposed in this paper to predict the ultimate strength of cold-formed built-up I-section members affected by pure buckling mode (i.e., L, D and G) as well as interactive buckling mode (i.e., LD and LDG).

\section{Experimental program}

\subsection{Material properties}

The structural steel of the cold-formed column investigated in this study is Chinese Q235 steel. The material properties were obtained through three standard tensile coupon specimens according to the standard GB/T 228-2002 [19]. The tensile coupons were extracted along the longitudinal direction of the web of the tested sections. Table 1 summarizes the material information obtained from the test results. The obtained engineering stress-strain curves are shown in Fig.1, where the first number of the specimen label refers to the thickness of the plate (i.e., T1.2 means that the thickness is $1.2 \mathrm{~mm}$ ) and the second number refers to the repeated number.

\subsection{Test specimens}

In this study, two identical C-section columns were simply connected back-to-back to form an I-section column by self-drilling screws. The schematics of the section geometries of the C-section column and built-up columns are presented in Fig.2. The measured dimensions of the C-section columns, as well as the built-up columns, were summarized in Table 2 and Table 3, respectively. The test members were carefully labeled so that the type of the section, the cross-sectional dimension and the actual length of the specimens can be included, as is shown in Fig.3. The first character refers to the length type of the column, i.e., SC, MC and LC refer to a column with short, intermediate and long length, respectively. The first number in the label refers to the section type of the column, i.e., SC1 and SC3 refer to C-section stub columns and built-up 
I-section stub columns, respectively. The last number refers to the cross-sectional dimension type of the column, i.e., SC3-90 and SC3-140 refer to a built-up I-section stub column with the nominal width of the web being equal to $92 \mathrm{~mm}$ and $142 \mathrm{~mm}$, respectively.

Two set of screw arrangement were used to guarantee the built-up members bearing the load cooperatively (see Fig.4), where the nominal longitudinal screw spacing for MC3 type and LC3 type columns was $300 \mathrm{~mm}$ and that for SC type columns was $150 \mathrm{~mm}$. The screw arrangements were based on the observation of the actual situation in Cold-formed steel structures design. The smaller screw spacing at the ends of the column was used to facilitate the alignment and connecting the two C-section columns into an I-section column accurately. The nominal transverse screws spacing (i.e. $2 e$ in Fig.4) is $32 \mathrm{~mm}$ for C3-90 type columns and $53 \mathrm{~mm}$ for C3-140 type columns.

\subsection{Geometric imperfections}

The initial local and overall geometrical imperfections for the test members were measured in this study. The initial local measurements were performed on the surface of the test members, as is shown in Fig.5. A displacement transducer with an accuracy of $0.001 \mathrm{~mm}$, which attached to a guide, was used to perform the measurements. When testing the initial local geometrical imperfections, the cross sections were measured with an interval of $5 \mathrm{~mm}$ for each specimen along the longitudinal direction. The measured maximum absolute values of initial local geometric imperfection $\left(\delta_{l}\right)$ for each C-section column and built-up I-section column were listed in table 2 and 3, respectively.

Further, the initial overall geometrical imperfections of the test member with respect to the weak axis (x-direction in Fig.2) were also measured before testing. It is worth to mention, due to limited space between the web-flange junctions of a built-up column, the displacement transducer can not be placed along the direction in parallel to the weak axis of the cross-section, thus the initial imperfection along the $\mathrm{x}$-direction for the built-up specimens were measured at the web-flange connection line at the mid-length of the single specimens before the specimens were connected into a built-up I-section,. The measured maximum absolute values of overall geometrical imperfections $\left(\delta_{\mathrm{o}}\right)$ for the C-section columns were listed in table 2, while the average absolute values of the single specimens for each built-up column were listed in table 3.

\subsection{Test setup}


The uniaxial compression test was conducted for the investigated members on the test rig shown in Fig. 6(a) and 6(b). In order to fix the column, steel end plates with a thickness of $15 \mathrm{~mm}$ were welded to the ends of all the test members. The fix-fix ends were employed for the stub columns (SC type columns) to avoid the adverse effect of axial force shifting after the local and distortional buckling occurred [20]. On the contrary, the end plates of other test members were connected to a designed condition devices to model the pin-pin ends (See Fig.7). As a result, the calculating length for stub columns is assumed to be $L_{0}=l$, whereas it was $L_{0}=l+220 \mathrm{~mm}$ for other columns, where $l$ is the length of the specimen. Since there are L-shape holes on the top plate of the bidirectional hinged supports, it was not difficult to center the MC type and LC type columns.

Both strain and displacement measurements were performed for each column. The arrangement of the strain gauges and LDVTs can be found in Fig. 8 (a) and 8 (b). For stub columns, the strain gauges and LDVTs were positioned around the mid-height of the column. For other columns, the arrangement of strain gauges was the same as stub columns, whereas the LDVTs were positioned at the middle height, 1/4 height and 3/4 height of the column, respectively. In addition, a total of 9 LDVTs were employed to measure the deformation of designed condition devices (labeled as D1 D5 and D16 19 in Fig. 8 (b)).

The compressive load was applied on the top end of the column by using a capacity servo-controlled hydraulic jack with an approximate $1 \mathrm{kN} / \mathrm{min}$ loading rate. The load, deflections and strains were measured simultaneously by a data acquisition system and recorded on a computer.

\section{Test Results}

\subsection{Buckling behaviors of the test members}

\subsubsection{SC type column}

As an example, Fig.9 shows the failure modes of the specimen SC1-90-A3 and SC3-90-A3, respectively. As it can be seen in the Fig.9 (a), local buckling occurred first as the compression load increased, regardless of the specimen section type. Nevertheless, since the investigated cold-formed members show a stable post-local-buckling strength reserve, the column can still bear the subsequent compression load. Then, with load continually increasing, the out-of-plane deformation due to local buckling increased significantly, as is shown in Fig.9 (b). Ultimately, it was observed that both the SC1-90 and the SC3-90 type columns failed in 
the local buckling mode Fig.9 (c).

On the contrary, for the SC-140 type columns, the distortional buckling occurred (Fig. 10 (b)) in a short time after the local buckling occurred (Fig. 10 (a)) on the specimen. Nonetheless, both the SC1-140-A3 and SC3-140-A3 specimens displayed a significant post-buckling strength, even though a complex interaction between the local and distortional buckling existed in this specimen type. However, the magnitude of the out-of-plane deformation due to distortional buckling was observed to be much larger than that of local buckling. As a result, the local buckling was overshadowed by the distortional buckling, which made the columns seem to fail in a pure distortional buckling mode (see Fig.10 (c)).

\subsubsection{MC type column}

Similar to the behavior of the SC type columns, local buckling was observed to occurred first for the MC type column (see Fig. 11 and 12), regardless of the section type being investigated. However, there was a quite different structural response between the MC1 type columns and the MC3 type columns: the MC1 type columns were observed to lose its bearing capacity soon after the local buckling occurred, whereas the MC3 type columns exhibited a significant post-local-buckling strength. Such a phenomenon is due to the fact that the local buckling load of the MC1 type column is quite similar to its global buckling counterpart, which leads to a significant strength erosion due to the occurrence of the local-global interaction. However, this is not holding true for the MC3 type built-up columns due to its superior overall buckling resistant by changing the cross-sectional geometry property.

The different structural response observed above resulted in quite different failure modes for the MC1 type columns and the MC3 type columns. As shown in Fig.11 (b) and Fig.12 (b), the MC1 type columns failed in an LG interactive mode, regardless of the section type being assessed. However, the failure mode for the MC3 type columns was an LDG interactive mode.

\subsubsection{LC type column}

In the test, all the LC type columns failed in a pure global buckling mode with none of the local buckling and other forms cross-section distortions visually observed, regardless of the section type. Therefore, the photos concerning the deformation of LC type columns were not included in this paper.

\subsection{Load versus axial displacement curves}


Fig. 13 showed the obtained results in the compression test for each tested specimen. Load vs. axial displacement curves were presented. It was observed that for the three repeated tests conducted for each type of specimen at the loading stage, failure load and the unloading stage was very similar. Such a phenomenon shows that the obtained results of each tested specimen in the compression test are reliable. However, the slight difference was obtained for the MC3-140-A1 specimen with MC3-140-A2 and MC3-140-A3 specimens. One possible reason is the adjustments in end-support devices since a small curvature of the load vs. axial displacement curve is observed at the loading stage. Therefore, the obtained ultimate strength for MC3-140-A1 members may be unreliable.

Further, it should be pointed out that, since the force loading was adopted in the compression test, the actual load vs. axial displacement curves at the unloading stage can not be obtained if the tested specimen failed abruptly, such as MC3-90 specimens, and thus slight difference of the load vs. axial displacement curves can also be obtained for the three repeated tests at unloading stage.

\subsection{Ultimate load for the test members}

The ultimate load and the failure mode of the all test members were presented in Table 2 and Table 3 , where the symbol $P_{\mathrm{u}}$ in the tables refers to the ultimate load. Observing the results in Table 2 and Table 3, the following aspects deserve to be mentioned:

(1) Firstly, it can be clearly seen in Table 2 that the occurrence of buckling caused substantial strength erosions for C-section columns, and thus the value of $P_{\mathrm{u}}$ for each specimen is always lower than that of $P_{\mathrm{y}}$. Moreover, the value of $P_{\mathrm{u}} / P_{\mathrm{y}}$ decreased as one travels from $\mathrm{L}$ to $\mathrm{LD}, \mathrm{LG}$ and $\mathrm{G}$, where the mean value of $P_{\mathrm{u}} / P_{\mathrm{y}}$ is $0.75,0.54,0.45$ and 0.15 for SC1-90, SC1-140, MC1-90 and LC1-90 specimens, respectively. The reason, which results in such a phenomenon, can be ascribed to the different buckling and post-buckling behavior of each type of buckling mode. The detailed information about the buckling and post-buckling behavior of C-section columns can be referred to Ref. [4, 12 18].

(2) Similarly, the strength erosions for built-up I-section columns can also be found in Table.3. However, compared with C-section column in Table.2, the buckling behavior of built-up I-section columns is more complicated due to the occurrence of LDG interactions. According to the authors' knowledge, there seems no research concerning the structural behavior of the built-up I-section columns affected by LDG interactions. 
Therefore, a DSM-based method will be explored in Section 3 to quantify the strength erosion of cold-formed built-up I-section columns affected by LD and LDG interactions.

(3) Finally, It can be clearly found in Table 2 and 3 that the ultimate load of the LC3 type built-up columns, which failing in a pure global buckling mode, is significantly higher than their corresponding LC1 type C-section counterparts. Such a result proves that the built-up column specimens have a superior overall buckling resistant than that of the $\mathrm{C}$-section column specimens. However, the above result is not holding true for the SC3 type column, where the ultimate load of the SC3 type column is right approximately two times of that of the corresponding SC1 type counterpart. This result is due to the fact that the local buckling, which generally occurred at short wavelengths, cannot be significantly restricted by the screws, as is illustrated in Ref. [7].

\section{Design methods}

Currently, two basic design methods for cold-formed steel members are formally available in design specifications in North America [1], namely the effective width method (EWM) and direct strength method (DSM). Compared with the EWM, the DSM is more favorable in this paper since this method can be used to predict the ultimate strength of the columns affected by buckling interactions. However, the current direct strength method does not cover the design of built-up sections. Therefore, the appropriateness of direct strength method for the cold-formed built-up I-sections columns will be evaluated in this paper.

In the following contents, a simplified elastic analysis model was proposed in Section 3.1 for predicting the elastic local, distortional and global buckling load of the built-up I-section columns. Subsequently, three basic strength curves (i.e., local, distortional and global buckling strength curves adopt by AISI [1] and AS/NZS [25] codes) and the modified local buckling strength curve proposed by Kumar and Kalyanaraman [26] were briefly reviewed in section 3.2.1 and 3.2.2, respectively. In addition, the famous LD $\left(P_{\mathrm{NLD}}\right)$ and LDG $\left(P_{\mathrm{NLDE}}\right)$ interactive strength curves proposed by Schafer [27] were also reviewed in section 3.2.3. Ultimately, based on the research of Kumar and Kalyanaraman [26], novel LD and LDG interactive curves were proposed in section 3.2.4, which aims to explore a more rational strength curve for the cold-formed built-up I-section column failing in LD and LDG interactive mode than the $P_{\mathrm{NLD}}$ and $P_{\mathrm{NLDE}}$ curves proposed by Schafer [27]. 


\subsection{Elastic buckling load}

The application of the DSM to predict the structural behavior of the cold-formed steel members requires previous determination of the corresponding critical buckling load values (i.e., elastic local, distortional and overall buckling load), which can be obtained by means of rational elastic analysis, such as finite strip software CUFSM proposed by Schafer [21,22]. The elastic buckling analysis using the finite strip method requires the given section to be uniform along the longitudinal direction. However, the built-up sections connected by screws don't meet this requirement, and thus the built-up sections cannot be directly employed for computation in the finite strip method. Therefore, based on the test results as well as other test results from the literature, a set of simplified elastic buckling model was proposed in the following contents to facilitate predicting the ultimate strength of cold-formed built-up I-section columns.

\subsubsection{Elastic local buckling load}

In the test, a clear evidence was obtained that the ultimate strength of a built-up I-section column failed in local buckling mode is approximately two times of that of corresponding C-section counterpart with screw spacing being larger than the local buckling half-wavelength of the corresponding C-section parts. In this scenario, a single C-section model was used in Fig.14 for determining the elastic local buckling load of the built-up I-section column with screw spacing being larger than the local buckling half-wavelength of the corresponding C-section parts. However, it should be pointed out that the obtained elastic local buckling load of the model may be inconsistent with the actual value of the built-up I-sections. Nonetheless, the effect of ignoring the restraint of screws on the ultimate strength is still modest, which have also been experimentally and numerically verified by $\mathrm{Li}$ and $\mathrm{Li}$ [7] for built-up box section column and by Wang for built-up I-section column [18].

\subsubsection{Elastic distortional buckling load}

In general, the distortional buckling half-wavelength of a column is larger than the local buckling one. Therefore, the screw spacing may be smaller than the buckling half-wavelength, and thus the distortional buckling deformation may be affected due to the restraint effect of the screws on the web. Nonetheless, the impact of screws is still limited since the deformation of distortional buckling mainly accumulated in the lip-web junctions [23], which can not be significantly restraint by screws. Consequently, the same model of 
the local buckling in Fig.14 was proposed for determining the elastic distortional buckling load.

Of course, the obtained elastic distortional buckling load of the built-up I-section column may be more close to the actual situation if the restraint effect of fasteners is considered, but it may not be a favorable choice in this paper due to its complication and modest effect on the ultimate strength.

\subsubsection{Global buckling load}

One of the major advantages of the built-up I-sections is that the torsion stiffness can be significantly improved by changing the section type from a single-symmetrical section to a double-symmetrical section. According to the AISI code [1], when determining the flexure buckling load of the built-up columns, the modified slenderness method is specified. Such a requirement is based on the research of the hot-rolled batten column, whose flexure buckling behavior can be significantly affected due to the shear deformation of the batten plates [24]. However, such a usage is not suitable for the cold-formed I-section built-up column since the effect of the shear deformation of screws can be ignored due to the small distance between two individual members. As a result, the elastic global buckling loads of the cold-formed built-up I-section columns can be obtained by considering the cross section as a whole (Fig.14), which had been experimentally verified by Stone and LaBoube [5].

\subsection{Direct strength method}

\subsubsection{Current direct strength method}

The current direct strength method (DSM), adopted in AISI [1] and the AS/NZS [25], takes the overall buckling (E), distortional buckling (D) and the interaction between local and overall buckling (L+E) into account, which yields:

$$
\begin{gathered}
P_{D 1}=\min \left(P_{n e}, P_{n l e}, P_{n d}\right) \\
P_{n e}= \begin{cases}\left(0.658^{\lambda_{c}^{2}}\right) P_{y} & \lambda_{c} \leq 1.5 \\
\left(\frac{0.877}{\lambda_{c}^{2}}\right) P_{y} & \lambda_{c}>1.5\end{cases} \\
P_{n l e}=\left\{\begin{array}{cc}
P_{n e} & \lambda_{l} \leq 0.776 \\
{\left[1-0.15\left(\frac{P_{c r l}}{P_{n e}}\right)^{0.4}\right]\left(\frac{P_{c r l}}{P_{n e}}\right)^{0.4} P_{n e}} & \lambda_{l}>0.776
\end{array}\right.
\end{gathered}
$$




$$
P_{n d}=\left\{\begin{array}{cl}
P_{y} & \text { if } \lambda_{d} \leq 0.561 \\
{\left[1-0.25\left(\frac{P_{c r l}}{P_{y}}\right)^{0.6}\right]\left(\frac{P_{c r l}}{P_{y}}\right)^{0.6} P_{y}} & \text { if } \lambda_{d}>0.561
\end{array}\right.
$$

where $\lambda_{\mathrm{c}}=\sqrt{P_{\mathrm{y}} / P_{\text {cre }}}, P_{\mathrm{y}}=A_{\mathrm{g}} f_{\mathrm{y}} ; \lambda_{l}=\sqrt{P_{\mathrm{ne}} / P_{\text {crl }}}, P_{\text {crl }}=A_{\mathrm{g}} f_{\text {crl }} ; \lambda_{\mathrm{d}}=\sqrt{P_{\mathrm{y}} / P_{\text {crd }}}, P_{\text {crl }}=A_{\mathrm{g}} f_{\text {crd }} ; A_{\mathrm{g}}$ is the gross cross-section area; $P_{\text {cre }}, P_{\text {crl }}$ and $P_{\text {crd }}$ are the elastic critical local, distortional and overall buckling load, respectively. $P_{\text {ne }}, P_{\text {nle }}$ and $P_{\text {nd }}$ are the nominal overall buckling strength, local-global interaction buckling strength and distortional buckling strength, respectively.

Since one has $P_{\mathrm{nle}} \leq P_{\mathrm{ne}}$, the actual nominal strength of the column always corresponds to the lower of two values: the local-global interactive $\left(P_{\text {nle }}\right.$ in Eq.3b) and distortional $\left(P_{\text {nd }}\right.$ in Eq.3c) failure loads.

\subsubsection{Modified direct strength method}

The local buckling strength curve proposed by Schafer [27] was modified in this section. The strength curve proposed by Kumar and Kalyanaraman [26] was adopted since it provides a more accurate estimation than Schafer's curve due to the consideration of the difference of web-flange interaction at the elastic local buckling stage and at the post-local-buckling stage, which yields

$$
P_{n l} *=\left\{\begin{array}{cc}
P_{y} & \lambda_{l} \leq 0.6 \\
{\left[1-\alpha\left(\frac{P_{c r l}}{P_{y}}\right)^{\beta}\right]\left(\frac{P_{c r l}}{P_{y}}\right)^{\beta} P_{n e} \leq P_{n l, \text { max }}^{*}} & \lambda_{l}>0.6
\end{array}\right.
$$

where

$$
\begin{gathered}
\alpha_{1}=0.27(2-\mu) \\
\beta=\frac{1}{100}(50-7 \mu) \geq 0.35 \\
\mu=\max \left[h / b,(b / h)^{0.6}\right] \\
P_{n l, \max }^{*}= \begin{cases}{\left[1-0.12\left(\frac{P_{c r l}}{P_{y}}\right)^{0.15}\right]\left(\frac{P_{c r l}}{P_{y}}\right)^{0.15} P_{y} \quad h / b \geq 1.00} \\
{\left[1-0.20\left(\frac{P_{c r l}}{P_{y}}\right)^{0.32}\right]\left(\frac{P_{c r l}}{P_{y}}\right)^{0.32} P_{y}} & h / b<1.00\end{cases}
\end{gathered}
$$

where $h$ and $b$ are the depth of the web and the width of the flange, respectively.

Similarly, it is possible to replace $P_{\mathrm{y}}$ (Eq.4 and 5) with $P_{\text {ne }}$ to handle column failing in LG interactions, as is done by current DSM (Eq.3b), which prompt 


$$
P_{n l e}^{*}=\left\{\begin{array}{cc}
P_{n e} & \lambda_{l} \leq 0.6 \\
{\left[1-\alpha\left(\frac{P_{c r l}}{P_{n e}}\right)^{\beta}\right]\left(\frac{P_{c r l}}{P_{n e}}\right)^{\beta} P_{n e} \leq P_{n l e, \text { max }}^{*}} & \lambda_{l}>0.6
\end{array}\right.
$$

As a result, the ultimate strength of the built-up I-section column by taking the above local-global interaction curve (Eq.6) into consideration can be expressed as

$$
P_{D 2}=\min \left(P_{n e}, P_{n l e}{ }^{*}, P_{n d}\right)
$$

\subsubsection{Direct strength method for interactive failures involving distortion}

The current direct strength method cannot be directly applied to cold-formed members affected by mode interaction phenomena involving distortional buckling, namely (1) local-distortional (LD), distortional-global (DG) and (3) local-distortional-global (LDG). Followed the similar procedure adopted to handle the local-global interactive mode in Eq.3b, Shafer proposed an expression which intended to account for the detrimental effect of the LD interactive mode [27], which yield

$$
P_{n l d}=\left\{\begin{array}{cc}
P_{n d} & \lambda_{l d} \leq 0.776 \\
{\left[1-0.15\left(\frac{P_{c r l}}{P_{n d}}\right)^{0.4}\right]\left(\frac{P_{c r l}}{P_{n d}}\right)^{0.4} P_{n d}} & \lambda_{l d}>0.776
\end{array}\right.
$$

where $\lambda_{l \mathrm{~d}}=\sqrt{P_{\mathrm{nd}} / P_{\mathrm{crl}}}$.

Similarly, it is also possible to handle the distortional-global interactive mode, and therefore, the nominal strength addressing distortional-global interactive failure may be given as

$$
P_{n d e}=\left\{\begin{array}{cc}
P_{n e} & \lambda_{d e} \leq 0.561 \\
{\left[1-0.25\left(\frac{P_{c r d}}{P_{n e}}\right)^{0.6}\right]\left(\frac{P_{c r d}}{P_{n e}}\right)^{0.6} P_{n e}} & \lambda_{d e}>0.561
\end{array}\right.
$$

where $\lambda_{\mathrm{de}}=\sqrt{P_{\mathrm{ne}} / P_{\text {crd }}}$.

Furthermore, based on the philosophy of Schafer's method, the nominal strength of the cold-formed members experiencing triple (LDG) interactions is related to three basic elastic buckling load, namely the local $\left(P_{\text {crl }}\right)$, distortional $\left(P_{\text {crd }}\right)$ and global $\left(P_{\text {cre }}\right)$. Therefore, the nominal strength addressing triple (LDG) interactive failure may be given as

$$
P_{\text {nlde }}=\left\{\begin{array}{cc}
P_{\text {nde }} & \lambda_{\text {lde }} \leq 0.776 \\
{\left[1-0.15\left(\frac{P_{c r l}}{P_{\text {nde }}}\right)^{0.4}\right]\left(\frac{P_{c r l}}{P_{\text {nde }}}\right)^{0.4} P_{\text {nde }}} & \lambda_{\text {lde }}>0.776
\end{array}\right.
$$

where $\lambda_{\text {lde }}=\sqrt{P_{\text {nde }} / P_{\text {crl }}}$. 


\subsubsection{Modified direct strength method for interactive failures involving distortion}

As is mentioned before, the local buckling strength curve proposed by Kumar and Kalyanaraman [26] can provide a more accurate estimate than the current direct strength method for columns failed in local buckling. Thus, for the purpose of obtaining a more rational estimate for the cold-formed members experiencing LD interaction and LDG interactions, the above LD interactive equation (Eq.9) and LDG (Eq.10) interactive equation were further modified here, which yield

$$
\begin{gathered}
P_{n l d} *=\left\{\begin{array}{cc}
P_{n d} & \lambda_{l d} \leq 0.6 \\
{\left[1-\alpha\left(\frac{P_{c r l}}{P_{n d}}\right)^{\beta}\right]\left(\frac{P_{c r l}}{P_{n d}}\right)^{\beta} P_{n d} \leq P_{n l d, \text { max }}^{*}} & \lambda_{l d}>0.6
\end{array}\right. \\
P_{n l d e} *=\left\{\begin{array}{cl}
P_{n d e} & \lambda_{\text {lde }} \leq 0.6 \\
{\left[1-\alpha\left(\frac{P_{c r l}}{P_{n d e}}\right)^{\beta}\right]\left(\frac{P_{c r l}}{P_{n d e}}\right)^{\beta} P_{n d e} \leq P_{n l d, \text { max }}^{*}} & \lambda_{\text {lde }}>0.6
\end{array}\right.
\end{gathered}
$$

where

$$
\left.P_{n l i, \max }^{*}\right|_{i=d, d e}= \begin{cases}{\left[1-0.12\left(\frac{P_{c r l}}{P_{i}}\right)^{0.15}\right]\left(\frac{P_{c r l}}{P_{i}}\right)^{0.15} P_{i}} & h / b \geq 1.00 \\ {\left[1-0.20\left(\frac{P_{c r l}}{P_{i}}\right)^{0.32}\right]\left(\frac{P_{c r l}}{P_{i}}\right)^{0.32} P_{i}} & h / b<1.00\end{cases}
$$

\section{Comparison of results from test and design method}

In this section, the validation of both the current direct strength (Eq.2) and the modified direct strength (Eq.7) for predicting the ultimate strength of the cold-formed built-up I-section columns was evaluated initially. The performance of the two methods was compared and verified by using the test results in this study as well as other test results in the literature [18] in Section 4.1. Then, in order to explore a more rational strength curve for the built-up I-section column failing in LD and LDG interactive mode, the aforementioned strength curves for interactive failures involving distortion (Eq.8 12) were investigated in Section 4.2 by using the test results. Ultimately, a novel direct strength method, which can be used to predict the ultimate strength of the cold-formed built-up I-section members affected by pure buckling mode (i.e., L, D and G) as well as interactive buckling mode (i.e., LD and LDG), were presented and validated in Section 4.3 .

\subsection{Current DSM and modified DSM}

The test strengths of the cold-formed built-up I-section columns in this paper, as well as the test results 
in the literature [18], were analyzed using the current direct strength method (CDSM) and the modified direct strength method (MDSM).The comparison results between the CDSM and MDSM were summarized in Table 4 and displayed in Fig.15 (a) (c).

The detail information of the tested members in Ref. [18] were tabulated in Table 5 and displayed in Fig.16, which includes the nominal cross-section dimension, column length, material properties and the deformation evolution of MC-3 member. It is worth to mention that the tested members in Ref. [18] were connected running perpendicular to cold-formed track sections with self-drilling screws (Fig.16). According to the researches of Telue and Mahendran $[28,29]$, the effective length of the cold-formed columns with such an end condition varied from 0.62 to 1.0 with increasing track to stub flexural rigidity ratio. Therefore, for the sake of obtaining a more rational strength estimate for LC type column in Table 4, which is more sensitive to the end conditions than other type columns, the effective length $L_{0}$ for the minor axis flexure buckling of the columns in Table 5 was assumed to be $0.75 l$.

The elastic local $\left(P_{\text {crl }}\right)$ and distortional buckling loads $\left(P_{\text {crd }}\right)$ in Table 4 were obtained from software CUFSM [21, 22] using the proposed calculation model in Fig.14. The cross-sectional dimensions adopted for performing the elastic buckling analysis were the measured dimensions for the specimens in this paper (i.e., the average value for the measured dimensions of the two single parts of a built-up column in Table.3) and the nominal dimensions for the specimens in Ref. [18] (Table.5). In some cases, when the conventional FSM method of software CUFSM cannot uniquely identify the buckling modes between local buckling and distortional buckling (such as SC3-140 specimens), the CFSM method of CUFSM was employed to determine the buckling half-wavelength and the corresponding buckling load, as is recommended by Li and Schafer [22].

According to the results in Table 4 and Fig.15 (a) (c), the following conclusions can be obtained:

(1) The prediction results obtained from the CDSM and MDSM are accurate and less scattered - the averages values of $P_{\mathrm{D} 1} / P_{\mathrm{u}}$ and $P_{\mathrm{D} 2} / P_{\mathrm{u}}$ equal to 1.00 and 1.04 , respectively; whereas the standard deviations of $P_{\mathrm{D} 1} / P_{\mathrm{u}}$ and $P_{\mathrm{D} 2} / P_{\mathrm{u}}$ equal to 0.12 and 0.13 , respectively. This result indicates that the proposed elastic buckling analysis model in Fig.13 can be used successfully in predicting the ultimate strength of the cold-formed built-up I-section column. 
(2) For the SC3-90 members failed in pure local buckling mode, the test results agree well with that obtained from the MDSM method. However, on the contrary, a clearly conservative result was obtained from the CDSM method. This result is mainly due to the fact that the CDSM does not consider the difference of web-flange interaction at the elastic local buckling stage and at the post-local buckling range, as is mentioned in Section 3.2.2, which results in an underestimated post-local-buckling strength reserve for the SC3-90 members.

(3) For the SC, MC and the SC3-140 type members, which failed in the LD interactive mode or the LDG interactive mode, the MDSM method provides an exceedingly overestimated prediction. The main reason which resulted in such a phenomenon can be ascribed to the adverse effect of distortional interactions. On the contrary, the CDSM seems to be more rational than MDSM. However, it may be inappropriate to directly conclude that the CDSM can be used successfully in estimating the strength of built-up column experiencing LD and LDG interactions. Indeed, the above rational prediction of CDSM method come at the expense of the underestimated of the post-local-buckling strength reserve can largely cancel out the adverse effect of ignoring the distortional interactions (ignoring the effect of distortional interactions can lead to a overestimated strength). In some case, if the above two effects cannot largely cancel out each other the CDSM can also lead to a clearly overestimated strength prediction, such as MC and SC members shown in table 4.

\subsection{The DSM and modified DSM for interactive failures involving distortion}

Since the clear evidence was obtained concerning the fact that LD and LDG interaction causes substantial ultimate strength erosion in cold-formed built-up I-section column, it was decided to explore a strength curve to quantify that erosion. Tables 6 provided the various DSM strength estimates for cold-formed built-up I-section column addressed the interactive failures involving distortion, namely predictions against (i) pure distortional ( $P_{\text {nd }}$ in Eq.3c), (ii) local-distortional interactive ( $P_{\text {nld }}$ in Eq.8), (iii) distortional-global interactive ( $P_{\text {nde }}$ in Eq.9), (iv) local-distortional-global interactive ( $P_{\text {ndle }}$ in Eq.10), (v) modified local-distortional interactive ( $P_{\text {nld* }}$ in Eq.11) and (vi) modified local- distortional-global interactive ( $P_{\text {ndle* }}$ in Eq.12). In addition, Fig. 17(a) (f) plotted the variation of the ratios $P_{\text {nd }} / P_{\mathrm{u}}, P_{\text {nde }} / P_{\mathrm{u}}, P_{\mathrm{nld}} / P_{\mathrm{u}}, P_{\mathrm{nld}} * / P_{\mathrm{u}}$, $P_{\text {nlde }} / P_{\mathrm{u}}$, and $P_{\text {nlde } *} / P_{\mathrm{u}}$ with $\lambda_{\text {le }}$ for the tested SC, MC, MC3-90, MC3-140 and SC3-140 members which failed 
in LD or LDG interactive mode.

Comparing the results in Table 6 and Fig.16 (a) (f), the following aspects deserve to be mentioned:

(1) The DSM distortional predictions $\left(P_{\mathrm{nd}} / P_{\mathrm{u}}\right.$ in Table.6) are generally very unsafe and highly scattered - the $P_{\mathrm{nd}} / P_{\mathrm{u}}$ values have average and standard deviation equal to 1.21 and 0.13 , with 7 excessively unsafe values $\left(P_{\mathrm{nle}^{*} / P_{\mathrm{u}}}>1.10\right)$.

(2) Almost all DSM estimates (Table.6) associated with distortional interactive failures are safe and less scattered. However, they become increasingly conservative as one travels from DG to LD and LDE $-P_{\mathrm{de}} / P_{\mathrm{u}}$, $P_{\text {nld } *} / P_{\mathrm{u}}, P_{\text {nlde }} * / P_{\mathrm{u}}, P_{\mathrm{ld}} / P_{\mathrm{u}}$ and $P_{\mathrm{nlde}} / P_{\mathrm{u}}$ averages equals $1.07,1.01,0.90,0.90$ and 0.71 , respectively.

(3) The DSM distortional - global curve $\left(P_{\text {nde }} / P_{\mathrm{u}}\right.$ in Fig.17 (b)) agree fairly well with the test results for $\lambda_{\mathrm{le}}<1.3$ (low slenderness range).However, it becomes unsafe for $\lambda_{\mathrm{le}}>1.3$ (moderate and high slenderness range). This is due to the fact that the post-local-buckling strength reserve is relatively small for one with low slenderness, which precluding the meaningful strength erosion addressed with distortional interactions. However, this is not the case for one with moderate and high slenderness range, which shows a significant post-local-buckling strength reserve.

(4) The DSM local - distortional predictions $\left(P_{\text {nld }} / P_{\mathrm{u}}\right.$ in Fig.17(c) $)$ are excessively conservative for SC and SC3-140 columns, which fail in LD interactive mode, whereas they are slightly conservative for other columns, which fail in LDG interactive mode. This is due to the fact that the underestimated post-local-buckling reserve for MC, MC3-90 and MC3-140 type column can largely cancel out the overestimated strength due to ignoring the occurrence of global buckling. However, it was not the case for SC and SC3-140 columns since no overestimated strength due to ignoring the occurrence of global buckling was expected.

(5) The DSM modified local-distortional predictions $\left(P_{\text {nld } * / P_{\mathrm{u}}}\right.$ in Fig.17 (d) $)$ are unsafe for MC, MC3-90 and MC3-140 columns. This is due to the fact that this curve cannot take the detrimental effect of global buckling into account.

(6) Compared with other curves in Fig.16, the modified local-distortional-global curve $\left(P_{\text {nlde }^{*} / P_{\mathrm{u}}}\right.$ in Fig.17(f)) is more favorable to predict the ultimate strength of cold-formed built-up I-section columns fail in LD and LDG interactive modes since (i) it never provide excessively unsafe predictions, which can be 
founded in $\mathrm{D}, \mathrm{DG}$ and $\mathrm{LD}^{*}$ curve, (ii) it can preclude the excessively conservative predictions due to the underestimated post-local-buckling reserve for columns, as is exhibited by $P_{\text {nlde }}$ curve in Fig.17 (e).

\subsection{Proposed DSM method}

The main purpose of this section is to explore a novel DSM method for the cold-formed built-up I-section columns, which can provide accurate predictions for column not only failing in pure buckling mode (i.e., L, D and G) but also failing in complex interactive buckling mode (i.e., LD interactive and LDG interactive). The biggest challenge for developing such a method is how to consider the detrimental effect of meaningful LD interactive mode and LDG interactive mode.

As is illustrated in Section 4.2, the modified LDG interactive curve (Eq.12) is more favorable than other curves for predicting the ultimate strength of cold-formed built-up I-section column failing in LD and LDG interactive mode. In addition, the differences between modified LD curve (Eq.11) and modified LDG curve (Eq.12) for predicting the ultimate strength of columns failing in LD mode are modest (see SC and SC3-140 column in table.4). Therefore, the modified LDG interactive curve (Eq.12) will be employed to develop a DSM-based method to predict the ultimate strength of column failing in LD and LDG interactive mode. However, such a curve cannot be directly extended to predicate columns failing in other pure buckling modes, such as pure local buckling which can lead to an excessively conservative prediction. Therefore, in this paper, a empirical rule will be developed to make LD and LDG safe check, i.e., if one maintains (i) the elastic local buckling load is smaller than elastic distortional buckling load $\left(P_{\mathrm{crl}}<P_{\mathrm{crd}}\right)$ and (ii) the local buckling strength $\left(P_{\mathrm{nl} *}\right)$ is higher than the elastic distortional buckling load $\left(P_{\mathrm{crd}}<P_{\mathrm{n}} *\right)$, the modified LDG interactive curve (Eq.12) is proposed as additional check. The first condition is proposed to ensure local buckling occurs first, while the second condition is adopted to ensure the post-local-buckling strength reserve is adequate so that the distortional buckling could occur as well. Moreover, it is worth to mention that, He and Zhou [15] also had proposed a similar empirical rule $\left(0.71 \leq P_{\text {crl }} / P_{\text {crd }} \leq 2.06\right)$ to check the ultimate strength of web-stiffened lipped channel columns failing in local-distortional interactive mode.

With the above empirical rule, a novel direct strength method (DSM-3) is proposed here as

$$
P_{D 3}=\left\{\begin{array}{cl}
\min \left(P_{n e}, P_{n l e}{ }^{*}, P_{n d}\right) & \text { if } P_{\text {crl }}>P_{\text {crd }} \text { or } P_{\text {crd }}>P_{\text {nl }} *^{*} \\
\min \left(P_{n e}, P_{n l e} *, P_{n d}, P_{n l d e} *\right) & \text { if } P_{\text {crl }}<P_{\text {crd }} \text { and } P_{\text {crd }}<P_{\text {nl e }}
\end{array}\right.
$$

The comparison between the tested result and proposed method (PDSM), as well as CDSM and MDSM 
method, are summarized in table 4 and further displayed in Fig.15 (a) (c), which prompt the following remarks:

(1) First of all, it should be pointed out that the proposed PDSM method provided accurate predictions for the ultimate strength of built-up I-section columns failing in LD and LDG interactive mode, with none excessively unsafe estimate $\left(P_{\mathrm{D} 3} / P_{\mathrm{u}} \geq 1.1\right)$. On the contrast, the CDSM provided 5 excessively unsafe estimates $\left(P_{\mathrm{D} 1} / P_{\mathrm{u}} \geq 1.1\right)$ and MDMS provided 8 excessively unsafe estimates $\left(P_{\mathrm{D} 2} / P_{\mathrm{u}} \geq 1.1\right)$.

(2) For C3-90 type column, which has the local buckling strength $\left(P_{1^{*}}\right)$ lower than corresponding elastic distortional buckling load $\left(P_{\text {crd }}\right)$, the MDSM and PDSM curve are coincident. As a result, the PDSM method cannot successfully in predicting the failure mode for MC3-90 type column. Nonetheless, the PDSM method can accurately predict the ultimate strength of MC3-90 type columns. Indeed, the occurrence of distortional interactions for MC3-90 type column is mainly caused by the second order effect since the local buckling strength $\left(P_{\mathrm{n} 1^{*}}\right)$ of the MC3-90 type is lower than the corresponding distortional buckling load $\left(P_{\text {crd }}\right)$, which precluding the meaningful strength erosion addressed with distortional interactions.

(3) It is clear in Fig.15 (c) that the PDSM method is slightly conservative than CDSM method, which results in an excessively safe estimate for the case of MC3-140-A1 $\left(P_{\mathrm{D} 3} / P_{\mathrm{u}}<0.8\right.$ in Table 4$)$. However, as is illustrated in section 2.2 the tested result of the MC3-140-A1 column is unreliable due to the adjustment of end supported devices. Therefore, the data of MC3-140-A1 can be omitted, and thus none of the excessively safe estimates can be provided by the DSM-3 method for the columns in Table 4 .

(4) Finally, according to the above comparison, it can be found that the proposed DSM-3 method is more favorable than other methods since it (i) takes the LD and LDG interactive buckling mode into account, (ii) never provide excessively unsafe predictions for column failing LD and LDG interactive mode and (iii) can accurately predict the ultimate strength of column failing in pure buckling mode (i.e., $\mathrm{L}$ and $\mathrm{G}$ ) as well as failing in complex interactive buckling mode (i.e., LD interactive and LDG interactive).

\section{Conclusions and remarks}

An experimental investigation and a novel direct strength method for the cold-formed built-up I-section columns were presented in this paper. Initially, a total of 18 compressed single C-section columns and 18 built-up I-section columns were tested, respectively. The cross-sectional dimension, the thickness and the 
length of the test members were varied in the test so as to cover a wide range of local, distortional and overall slenderness. Subsequently, due to the clear evidence obtained in the test that the LD and LDG interactions cause substantial ultimate strength erosion in cold-formed built-up I-section column, a novel direct strength method was proposed to quantify such an erosion. In order to verify and validate the proposed method, the test results in this paper as well as other test results in Ref.[18] were compared with the results calculated from the current direct strength method (CDSM) [1,25], the modified direct strength proposed [26] (MDSM) and the proposed method (PDSM) in this paper, respectively. The main conclusion obtained in this paper can be summarized as follows:

(1) The structure response of the cold-formed built-up I-section column in this study was significantly affected by the occurrence of local-distortional and local-distortional-global interactions. The complex multiple interactions effects resulted in a significant strength erosion for the tested built-up columns.

(2) The local buckling cannot be restrained for cold-formed I-section columns when the screw spacing is larger than the local buckling half-wavelength of the corresponding C-section parts. Under such a circumstance, the local buckling strength of the cold-formed built-up I-section column is approximately two times of that of the corresponding C-section parts.

(3) The CDSM and MDSM can lead to excessively unsafe estimates for built-up I-section columns due to the lack of consideration of strength erosions caused by LD and LDG interactions. However, the new method (PDSM) proposed in this paper can accurately predict the ultimate strength of the columns failed in a pure buckling mode (i.e., L and G) and a complex interactive buckling mode (i.e., LD and LDG).

(4) Although the new method proposed in this paper can be used to predict the ultimate strength of the built-up I-section columns, it should be pointed out that the proposed method is only validated for the range $1.0 \leq \lambda_{l} \leq 1.7$ due to lack of information on this form of columns. As a result, further researches are still required to validate the proposed method with $\lambda_{\mathrm{le}}$ out of the range $1.0 \leq \lambda_{\mathrm{le}} \leq 1.7$.

\section{Acknowledgement}

The authors are sincerely appreciated to the financial support by the National Science Foundation of China (No. 51508029) and by the Research Fund for Doctoral Program of Higher Education of China (No. 20110205110006). 


\section{References}

[1] American Iron Steel Institute. AISI. North American specification for the design of cold-formed steel structural members, Washington, DC; 2007.

[2] R. Zandonini. Stability of compact built-up struts: experimental investigation and numerical simulation. Construzioni metalliche, No. 4, 1985.

[3] F. Aslani, S.C. Goel. An analytical criterion for buckling strength of built-up compression members. Eng J 28(4) (1991) 159-68 (American Institute of Steel Construction, Inc., Chicago, IL).

[4] B.W. Schafer. Review: the direct strength method of cold-formed steel member design. J. Constr Steel Res. 64 (2008) 766-78.

[5] T.A. Stone, R.A. Laboube. Behavior of cold-formed steel built-up I-sections. Thin-Walled Struct. 43(12) (2005) 1805-17.

[6] J. Whittle, C. Ramseyer. Buckling capacities of axially loaded, cold-formed, built-up C-channels. Thin-Walled Struct. 47 (2009) 190-201.

[7] Li Yuanqui, Li Yinglei, S. Wang, Z. Shen, Ultimate load-carrying capacity of cold-formed thin-walled columns with built-up box and I section under axial compression, Thin-Walled Struct. 79 (2014) 202-217.

[8] J.H. Zhang, B. Young. Compression tests of cold-formed steel I-shaped open sections with edge and web stiffeners. Thin-Walled Struct. 52 (2012) 1-11.

[9] J.H. Zhang, B. Young. Numerical investigation and design of cold-formed steel built-up open section columns with longitudinal stiffeners. Thin-Walled Struct. 89 (2015) 178-191.

[10] Li Yuanqui, Li Yinglei, Shen Zuyan. Investigation on flexural strength of cold-formed thin-walled steel beams with built-up box section. Thin-Walled Struct. 107 (2016) 66-79.

[11] L. Wang, B. Young. Beam tests of cold-formed steel built-up sections with web perforations. J. Constr Steel Res. 115 (2015) 18-33.

[12] D. Yang, G.J. Hancock. Compression tests of high strength steel channel columns with interaction between local and distortional buckling. J Struct Eng (ASCE). 130 (12) (2004) 1954-63.

[13] Silvestre BW, Dinis PB, Camotim D. Direct strength method for lipped channel columns and beams affected by local-plate/distortional interaction. In: Proceedings of 18th international specialty conference on cold-formed steel structures. 2006. p. 1-18.

[14] J. Loughlan, N. Yidris, K. Jones. The failure of thin-walled lipped channel compression members due to coupled local-distortional interactions and material yielding, Thin-Walled Struct. 61 (6) (2012) 14-21.

[15] Z. He, X. Zhou, Z. Liu, et al. Post-buckling behaviour and DSM design of web-stiffened lipped channel columns with distortional and local mode interaction. Thin-Walled Struct. 84 (2014) 189-203.

[16] E.S.D. Santos, E.M. Batista, D. Camotim. Experimental investigation concerning lipped channel columns undergoing local-distortional-global buckling mode interaction. Thin-Walled Struct. 54 (2) (2012) 19-34.

[17] P.B. Dinis, E.M. Batista, D. Camotim, et al. Local-distortional-global interaction in lipped channel columns: Experimental results, numerical simulations and design considerations. Thin-Walled Struct. 61 (6) (2012) 2-13.

[18] Q. Wang. Compression tests and theoretical research of open section built-up cold-formed steel columns. Chang'an University; 2009.

[19] GB/T 228-2002. Metallic materials-tensile testing method of test at ambient temperature. Beijing, China; 2002.

[20] B. Young, K.J.R. Rasmussen. Shift of the effective centroid of channel columns. J Struct Eng (ASCE). 125 
(1998) 524-531.

[21] B.W. Schafer.CUFSM4.05 - finite strip buckling analysis of thin-walled members. Baltimore, U.S.A.:

Department of Civil Engineering, Johns Hopkins University, <http://www.ce.jhu.edu/bschafer/cufsm/>; 2012.

[22] Z. Li, B.W. Schafer. Application of the finite strip method in cold-formed steel member design. J. Constr Steel Res. 2010, 66(8):971-980.

[23] S.C.W. Lau, G.J. Hancock. Distortional buckling formulas for channel columns. J Struct Eng (ASCE). 113 (1987) 1063-78.

[24] S. Timoshenko. Theory of elastic stability. New York, NY: McGraw-Hill, Inc.; 1961.

[25] AS/NZS. Cold-formed steel structures. Sydney, Australia: Australian/New Zealand Standard, AS/NZS 4600:2005, Standards Australia; 2005.

[26] M.V.A. Kumar, V. Kalyanaraman. Design Strength of Locally Buckling Stub-Lipped Channel Columns. J Struct Eng (ASCE). 138 (11) (2012) 1291-1299.

[27] B.W. Schafer. Local, Distortional, and Euler Buckling of Thin-Walled. J Struct Eng (ASCE). 128 (3) (2002) 289-299.

[28] Y. Telue, M. Mahendran. Numerical modeling and design of unlined cold-formed steel wall frames. J. Constr Steel Res. 60 (2003) 1241-56.

[29] Telue Y, Mahendran M. Behaviour of cold-formed steel wall frames lined with plasterboard. Journal of Constructional Steel Research 57(4) (2001) 435-52. 


\section{Nomenclature}

$A_{\mathrm{g}} \quad$ gross cross-sectional area

$b$ width of flange

$d \quad$ width of lip

E Young's modulus

$e$ distance between the center line of screws and the web

$f_{\text {crd }} \quad$ critical elastic distortional buckling stress

$f_{\text {cre }} \quad$ critical elastic overall buckling stress

$f_{\text {crl }} \quad$ critical elastic local buckling stress

$f_{\mathrm{y}} \quad$ Yield stress

$h$ depth of web

$l$ length of column

$P_{\text {crd }} \quad$ critical elastic distortional buckling load

$P_{\text {cre }} \quad$ critical elastic overall buckling load

$P_{\text {crl }} \quad$ critical elastic local buckling load

$P_{\mathrm{D} 1} \quad$ nominal ultimate strength obtained by current direct strength method in NAS and AS/NZS [1, 25]

$P_{\mathrm{D} 2} \quad$ nominal ultimate strength obtained by the modified direct strength method in Ref. [26]

$P_{\mathrm{D} 3} \quad$ nominal ultimate strength obtained by the proposed method in this paper

$P_{\text {nd }} \quad$ nominal distortional buckling strength

$P_{\text {ne }} \quad$ nominal overall buckling strength

$P_{\mathrm{nl} *} \quad$ modified local buckling strength

$P_{\text {nld }} \quad$ nominal local-distortional interactive buckling strength

$P_{\text {nld* }} \quad$ modified local-distortional interactive buckling strength

$P_{\text {nle }} \quad$ nominal local-global interactive buckling strength

$P_{\text {nle* }} \quad$ modified nominal local-global interactive buckling strength

$P_{\text {nde }} \quad$ nominal distortional-global interactive buckling strength

$P_{\text {nlde }} \quad$ nominal local-distortional-global interactive buckling strength

$P_{\text {nlde* }} \quad$ modified local-distortional-global interactive buckling strength 


\section{List of captions:}

Table 1.Material properties

Table 2.Measured dimensions and failure loads of the test C-section columns

Table 3.Measured dimensions and failure loads of the test built-up I-section columns

Table 4.Comparison of test result $\left(P_{\mathrm{u}}\right)$ with Design method $-\mathrm{kN}$

Table 5.Nominal dimensions, material properties and test result of the test built-up I-section columns of Wang [18].

Table 6.Comparison of test result $\left(P_{\mathrm{u}}\right)$ with DSM estimates $\left(P_{\mathrm{n}}\right)-\mathrm{kN}$.

Figure 1.Stress vs. strain curve. (a) $t=1.2$. (b) $t=1.5$.

Figure 2.Cross-section geometry specimen: (a) C-section. (b) Built-up I-section.

Figure 3.Labeling rule of specimens

Figure 4. Arrangement of screw spacing: (a) SC3-90 type column. (b) SC3-140 type column. (c) MC3 and LC3 type column.

Figure 5.Location of local geometric imperfection measurements: (a) C-section column.(b) Built-up I-section column.

Figure 6.Test set-up: (a) SC type specimens. (b) MC and LC type specimens.

Figure 7.Bidirectional hinged support: (a) Configuration of the support. (b) Connections between the support and tested members

Figure 8.Arrangement of strain gauges and LVDTS: (a) SC type specimens. (b) MC and LC type specimens.

Figure 9.Comparison between the SC1-90-A3 and SC3-90-A3 specimens: (a) Local buckling occurred. (b) Right approaching the ultimate load. (c) Post-ultimate stage.

Figure 10.Comparison between the SC1-140-A3 and SC3-140-A3 specimens: (a) Local buckling occurred. (b) Interactions of local and distortional buckling occurred. (c) Post-ultimate stage

Figure 11.Comparison between the MC1-90-A2 and MC3-90-A1 specimens: (a) local buckling occurred. (b) Right approaching the ultimate load.

Figure 12.Comparison between the MC1-140-A1 and MC3-140-A3 specimens: (a) local buckling occurred. (b) Right approaching the ultimate load.

Figure 13.Load vs. Axial displacement curves for the tested members: (a) C1-90 type C-section columns. (b) C3-90 type built-up columns (c) C1-140 type C-section columns. (d) C3-140 type built-up columns

Figure 14.Cross-section assumptions for the calculation of design strength of I-shaped sections: (a) Local and distortional buckling load. (b) Overall buckling load. 
Figure 15.Comparison of design method and the test result: (a) C3 type built-up column in [18]. (b) C3-90 type built-up column in this paper. (c) C3-140 type built-up column in this paper.

Figure 16.Deformation evolutions of MC-3 members in Ref. [18]: (a) Before testing. (b) Right approaching the ultimate load (c) Front view at post-ultimate stage. (d) Side view at post-ultimate stage.

Figure 17.Comparisons between DSM estimates and test result for column failing in LD and LDG interactive mode: (a) $P_{\text {nd }} / P_{\text {n }}$ vs $\lambda_{\text {le }}$, (b) $P_{\text {nde }} / P_{\text {n vs }} \lambda_{\text {le }}$, (c) $P_{\text {nld }} / P_{\text {n vs }} \lambda_{\text {le }}$, (d) $P_{\text {nld } *} / P_{\text {n vs }} \lambda_{\text {le }}$, (e) $P_{\text {nlde }} / P_{\text {n vs }} \lambda_{\text {le }}$, (f) $P_{\mathrm{nlde}} * / P_{\mathrm{n}}$ vs $\lambda_{\mathrm{le}}$. 
Tables

Table 1 Material properties

\begin{tabular}{|c|c|c|c|c|c|c|c|}
\hline \multirow{2}{*}{ Specimens } & \multicolumn{2}{|c|}{ Yield stress } & \multicolumn{2}{|c|}{ Ultimate tensile stress } & \multicolumn{2}{|c|}{ Elastic module } & \multirow{2}{*}{ Elongation $(\%)$} \\
\hline & $f_{\mathrm{y}}(\mathrm{Mpa})$ & Mean value & $f_{\mathrm{u}}(\mathrm{Mpa})$ & Mean value & $E\left(10^{5} \mathrm{MPa}\right)$ & Mean value & \\
\hline $\mathrm{T} 1.2-1$ & 317.8 & & 374.6 & & 2.18 & & 34.3 \\
\hline $\mathrm{T} 1.2-2$ & 316.3 & 321.5 & 366.7 & 374.1 & 2.11 & 2.16 & 31.4 \\
\hline $\mathrm{T} 1.2-3$ & 330.5 & & 381.0 & & 2.19 & & 32.9 \\
\hline $\mathrm{T} 1.5-1$ & 301.0 & & 368.3 & & 2.04 & & 34.1 \\
\hline $\mathrm{T} 1.5-2$ & 308.4 & 305.4 & 374.0 & 369.7 & 2.06 & 2.05 & 34.0 \\
\hline $\mathrm{T} 1.5-3$ & 306.7 & & 366.7 & & 2.05 & & 33.9 \\
\hline
\end{tabular}

Table 2 Measured dimensions and failure loads of the test C-section columns

\begin{tabular}{|c|c|c|c|c|c|c|c|c|c|c|c|c|c|c|}
\hline \multirow{2}{*}{ Specimen } & \multirow{2}{*}{$l(\mathrm{~mm})$} & \multicolumn{2}{|c|}{$\begin{array}{c}\text { Geometric } \\
\text { imperfection(mm) }\end{array}$} & \multicolumn{7}{|c|}{ Cross-section dimension(mm) } & \multicolumn{4}{|c|}{ Test results(kN) } \\
\hline & & $\delta_{l}$ & $\delta_{\mathrm{o}}$ & $h$ & $b_{1}$ & $b_{2}$ & $d_{1}$ & $d_{2}$ & $t$ & $A\left(\mathrm{~mm}^{2}\right)$ & $P_{\mathrm{u}}$ & $P_{\mathrm{y}}$ & $P_{\mathrm{u}} / P_{\mathrm{y}}$ & Mode \\
\hline LC-90-A1 & 3033 & 0.341 & 1.213 & 94.5 & 43.0 & 43.5 & 14.5 & 15.5 & 1.19 & 251.1 & 11.5 & 80.7 & 0.14 & G \\
\hline LC-90-A2 & 3033 & 0.412 & 1.504 & 92.8 & 40.8 & 42.2 & 15.2 & 14.8 & 1.18 & 242.8 & 11.6 & 78.1 & 0.15 & G \\
\hline LC-90-A3 & 3033 & 0.327 & 1.306 & 92.2 & 42.0 & 41.8 & 13.8 & 15.5 & 1.18 & 242.3 & 12.3 & 77.9 & 0.16 & G \\
\hline MC-90-A1 & 1528 & 0.444 & 1.012 & 93.0 & 42.2 & 42.0 & 16.2 & 14.0 & 1.18 & 244.7 & 33.7 & 78.7 & 0.43 & LG \\
\hline MC-90-A2 & 1526 & 0.471 & 1.233 & 93.0 & 42.0 & 43.0 & 13.0 & 14.0 & 1.18 & 241.9 & 34.6 & 77.8 & 0.44 & LG \\
\hline MC-90-A3 & 1527 & 0.313 & 1.024 & 92.0 & 42.0 & 41.5 & 15.0 & 14.5 & 1.19 & 244.0 & 36.8 & 78.4 & 0.47 & LG \\
\hline SC-90-A1 & 303 & 0.263 & 0.101 & 94.8 & 43.7 & 42.2 & 14.0 & 14.0 & 1.19 & 248.4 & 64.3 & 79.8 & 0.81 & $\mathrm{~L}$ \\
\hline SC-90-A2 & 298 & 0.441 & 0.177 & 94.2 & 42.1 & 42.2 & 14.1 & 15.5 & 1.18 & 245.6 & 53.6 & 78.9 & 0.68 & $\mathrm{~L}$ \\
\hline SC-90-A3 & 298 & 0.331 & 0.153 & 94.7 & 42.8 & 42.1 & 14.2 & 14.8 & 1.19 & 248.2 & 60.8 & 79.8 & 0.76 & $\mathrm{~L}$ \\
\hline LC-140-A1 & 3032 & 0.429 & 1.212 & 140.0 & 42.5 & 43.0 & 14.0 & 15.5 & 1.48 & 377.4 & 17.6 & 121.3 & 0.15 & G \\
\hline LC-140-A2 & 3032 & 0.543 & 1.323 & 141.0 & 42.8 & 43.0 & 15.0 & 15.0 & 1.48 & 380.1 & 16.8 & 122.2 & 0.14 & G \\
\hline LC-140-A3 & 3033 & 0.552 & 1.227 & 142.2 & 42.3 & 41.5 & 14.5 & 15.8 & 1.48 & 379.3 & 16.8 & 122.0 & 0.14 & G \\
\hline MC-140-A1 & 1533 & 0.471 & 0.819 & 143.0 & 42.5 & 43.0 & 15.0 & 14.5 & 1.49 & 384.4 & 46.3 & 123.6 & 0.37 & LG \\
\hline MC-140-A2 & 1531 & 0.432 & 0.707 & 142.0 & 42.0 & 44.0 & 14.5 & 14.5 & 1.48 & 380.4 & 41.8 & 122.3 & 0.34 & LG \\
\hline MC-140-A3 & 1530 & 0.444 & 0.833 & 142.5 & 42.5 & 42.0 & 14.5 & 15.0 & 1.48 & 379.6 & 42.5 & 122.0 & 0.35 & LG \\
\hline SC-140-A1 & 451 & 0.561 & 0.122 & 144.0 & 44.0 & 42.3 & 14.0 & 46.8 & 1.48 & 430.8 & 64.1 & 123.2 & 0.52 & $\mathrm{LD}$ \\
\hline SC-140-A2 & 451 & 0.522 & 0.234 & 144.5 & 43.0 & 42.5 & 14.8 & 16.2 & 1.49 & 388.9 & 67.3 & 125.0 & 0.54 & $\mathrm{LD}$ \\
\hline SC-140-A3 & 451 & 0.477 & 0.241 & 145.0 & 43.0 & 43.8 & 12.8 & 16.5 & 1.49 & 389.0 & 69.5 & 125.1 & 0.56 & LD \\
\hline
\end{tabular}

Note: $1 . A_{\mathrm{g}}=\left(h+b_{1}+b_{2}+d_{1}+d_{2}\right) \times t ; P_{\mathrm{u}}$ is the ultimate strength; $P_{\mathrm{y}}=f_{\mathrm{y}} \times A_{\mathrm{g}}$, where $f_{\mathrm{y}}$ is the yield stress (Table.1).

1. L means local buckling, D means distortional buckling and $\mathrm{G}$ means global buckling

2. $\delta_{l}$ and $\delta_{\mathrm{o}}$ are the maximum initial local and overall geometry imperfections, respectively. 
Table 3 Measured dimensions and failure loads of the test built-up I-section columns

\begin{tabular}{|c|c|c|c|c|c|c|c|c|c|c|c|c|c|c|c|}
\hline \multirow{2}{*}{ Specimen } & \multirow{2}{*}{$l(\mathrm{~mm})$} & \multicolumn{2}{|c|}{$\begin{array}{c}\text { Geometric } \\
\text { imperfection(mm) }\end{array}$} & \multirow{2}{*}{ Part } & \multicolumn{7}{|c|}{ Cross-section dimension $(\mathrm{mm})$} & \multicolumn{4}{|c|}{ Test results $(\mathrm{kN})$} \\
\hline & & $\delta_{l}$ & $\delta_{o}$ & & $h$ & $b_{1}$ & $b_{2}$ & $d_{1}$ & $d_{2}$ & $t$ & $A\left(\mathrm{~mm}^{2}\right)$ & $P_{\mathrm{u}}$ & $P_{\mathrm{y}}$ & $P_{\mathrm{u}} / P_{\mathrm{y}}$ & Mode \\
\hline \multirow{2}{*}{ LC3-90-A1 } & \multirow{2}{*}{3033} & \multirow{2}{*}{0.412} & \multirow{2}{*}{1.012} & $\mathrm{a}$ & 94.5 & 43.0 & 43.5 & 14.5 & 15.5 & 1.18 & \multirow[b]{2}{*}{493.0} & \multirow[b]{2}{*}{42.6} & \multirow{2}{*}{158.5} & \multirow[b]{2}{*}{0.27} & \multirow[b]{2}{*}{ G } \\
\hline & & & & $\mathrm{b}$ & 91.8 & 43.2 & 40.5 & 14.4 & 15.2 & 1.19 & & & & & \\
\hline \multirow{2}{*}{ LC3-90-A2 } & \multirow{2}{*}{3038} & \multirow{2}{*}{0.521} & \multirow{2}{*}{1.076} & $\mathrm{a}$ & 92.0 & 41.8 & 42.2 & 14.8 & 15.0 & 1.19 & \multirow{2}{*}{487.5} & \multirow{2}{*}{39.9} & \multirow{2}{*}{156.7} & & \\
\hline & & & & $\mathrm{b}$ & 92.8 & 40.2 & 42.8 & 15.0 & 14.8 & 1.18 & & & & 0.25 & U \\
\hline & 3024 & 0234 & 1411 & $\mathrm{a}$ & 91.5 & 41.2 & 41.8 & 16.2 & 15.5 & 1.19 & & & & & \\
\hline LCD-90-AD & 3034 & 0.554 & 1.411 & $\mathrm{~b}$ & 91.8 & 41.8 & 40.5 & 14.8 & 14.5 & 1.19 & 481.4 & 41.2 & 150.1 & 0.20 & G \\
\hline & & & & $\mathrm{a}$ & 91.0 & 40.0 & 44.0 & 15.0 & 15.0 & 1.18 & & & & & \\
\hline MIC3-90-A1 & 1532 & 0.565 & 0.634 & $\mathrm{~b}$ & 93.0 & 43.0 & 41.5 & 15.0 & 14.0 & 1.19 & 487.6 & 88.8 & 156.8 & 0.57 & LDG \\
\hline$M C 300-2$ & 1531 & 0433 & 0521 & $\mathrm{a}$ & 92.5 & 42.0 & 43.0 & 14.5 & 14.0 & 1.20 & 4053 & 1030 & 1502 & 0.65 & $J D G$ \\
\hline $\operatorname{IV}(5-90-42$ & 1531 & 0.453 & 0.521 & $\mathrm{~b}$ & 92.0 & 43.0 & 43.5 & 15.0 & 15.0 & 1.19 & 495.3 & 105.0 & 159.2 & 0.05 & LDU \\
\hline $\mathrm{MC3}-90-\mathrm{A} 3$ & 1533 & 0613 & 0611 & $\mathrm{a}$ & 93.5 & 41.5 & 43.5 & 14.0 & 15.5 & 1.19 & 4888 & 977 & 1572 & 062 & $J D G$ \\
\hline 100 - & 1000 & 0.010 & 0.01 & $\mathrm{~b}$ & 93.0 & 42.0 & 42.0 & 135.0 & 14.0 & 1.18 & 700.0 & 1. & 101.2 & 0.02 & D \\
\hline & & & & $\mathrm{a}$ & 93.8 & 41.3 & 42.7 & 14.0 & 14.5 & 1.18 & & & & & \\
\hline 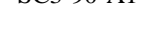 & 80 & 0.021 & 0.112 & b & 92.8 & 43.0 & 41.8 & 14.8 & 15.0 & 1.19 & 430.2 & 121.1 & 151.0 & 0.01 & L \\
\hline $\mathrm{SC} 300-2$ & 300 & 0374 & 0083 & $\mathrm{a}$ & 93.8 & 41.9 & 42.1 & 15.1 & 14.2 & 1.19 & 1041 & 1228 & 1588 & 0.84 & $\mathrm{~J}$ \\
\hline $505-90-82$ & 300 & 0.514 & 0.005 & $\mathrm{~b}$ & 93.8 & 41.8 & 42.2 & 14.8 & 15.5 & 1.19 & 494.1 & 152.8 & 158.8 & 0.84 & $\mathrm{~L}$ \\
\hline $\mathrm{SC} 300-43$ & 300 & 0452 & 0065 & $\mathrm{a}$ & 95.1 & 42.8 & 42.2 & 14.7 & 17.2 & 1.18 & 5027 & 1316 & 1614 & 082 & $\mathrm{~J}$ \\
\hline 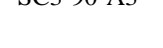 & 300 & $0.4 J 2$ & 0.000 & $\mathrm{~b}$ & 94.8 & 43.8 & 42.1 & 14.1 & 15.2 & 1.20 & 502.2 & 101.0 & 101.4 & 0.02 & $\mathrm{~L}$ \\
\hline $\mathrm{I} C 3-140-41$ & 3034 & & 0017 & $\mathrm{a}$ & 143.5 & 37.5 & 41.8 & 16.3 & 14.0 & 1.48 & & & & & \\
\hline 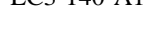 & 3004 & $0.0+0$ & 0.912 & $\mathrm{~b}$ & 140.8 & 42.0 & 41.5 & 16.0 & 15.5 & 1.49 & 155.1 & 49.2 & 230.8 & 0.21 & G \\
\hline & & & & $\mathrm{a}$ & 147.0 & 41.5 & 41.5 & 13.8 & 15.5 & 1.48 & & & & & \\
\hline LC $3-140-A 2$ & 5033 & 0.535 & 1.542 & $\mathrm{~b}$ & 141.5 & 42.3 & 42.0 & 16.0 & 14.5 & 1.47 & 100.5 & 40.9 & 232.3 & 0.20 & G \\
\hline $\mathrm{L} C 3-140-43$ & 3034 & 0462 & 1232 & $\mathrm{a}$ & 141.8 & 42.0 & 44.0 & 14.8 & 15.5 & 1.48 & 7686 & 502 & 2347 & 021 & $G$ \\
\hline LC3-140-A3 & 3034 & 0.402 & 1.252 & $\mathrm{~b}$ & 142.0 & 42.5 & 43.0 & 16.5 & 15.5 & 1.49 & 108.0 & 50.2 & 234.1 & 0.21 & G \\
\hline$M C 3140 \triangle 1$ & 1532 & 0652 & & $\mathrm{a}$ & 142.0 & 42.5 & 42.5 & 15.5 & 15.0 & 1.48 & & & & & \\
\hline N1C5-140-A1 & 1532 & 0.052 & 0.131 & $\mathrm{~b}$ & 144.5 & 42.5 & 43.5 & 14.5 & 14.5 & 1.50 & 170.4 & 124.0 & 235.3 & 0.53 & LDG \\
\hline$M C 3-140-42$ & 1533 & 0443 & & $\mathrm{a}$ & 142.0 & 43.0 & 42.0 & 15.0 & 15.0 & 1.48 & & & & & \\
\hline $110-3-140-A 2$ & 1535 & 0.443 & 1.112 & $\mathrm{~b}$ & 142.0 & 42.5 & 42.0 & 15.5 & 14.5 & 1.48 & 760.0 & 101.0 & 232.1 & 0.44 & LDG \\
\hline & & & & $\mathrm{a}$ & 141.0 & 43.5 & 40.0 & 14.0 & 15.0 & 1.48 & & & & & \\
\hline NIC-3-140-A3 & 1533 & 0.512 & $1.0 \angle 2$ & $\mathrm{~b}$ & 142.5 & 42.0 & 44.0 & 14.5 & 15.0 & 1.48 & 157.0 & 105.8 & 231.2 & 0.40 & LDG \\
\hline & & & & $\mathrm{a}$ & 144.2 & 44.1 & 41.9 & 13.9 & 15.0 & 1.48 & & & & & \\
\hline SC3-140-A1 & 451 & 0.656 & 0.173 & $\mathrm{~b}$ & 142.7 & 42.9 & 42.8 & 15.1 & 14.9 & 1.47 & 763.3 & 130.7 & 233.1 & 0.56 & LD \\
\hline & & & & $\mathrm{a}$ & 144.5 & 42.9 & 42.0 & 15.0 & 14.0 & 1.48 & & & & & \\
\hline SC3-140-A2 & 451 & 0.661 & 0.143 & $\mathrm{~b}$ & 144.2 & 43.0 & 42.8 & 14.8 & 13.9 & 1.48 & 765.3 & 139.6 & 233.7 & 0.60 & LD \\
\hline $\mathrm{SC} 3-140-43$ & 451 & 0541 & 0121 & $\mathrm{a}$ & 143.1 & 44.6 & 42.8 & 13.4 & 15.5 & 1.47 & 7620 & 1388 & 2327 & 060 & \\
\hline $5(5-140-A 5$ & 431 & 0.541 & 0.121 & $\mathrm{~b}$ & 143.0 & 42.9 & 42.3 & 14.0 & 15.0 & 1.48 & 102.0 & 138.8 & 232.1 & 0.00 & LD \\
\hline Note: $1 . A_{\mathrm{g}}=(h$ & $+b_{2}+d$ & 2) $\times t ; \quad I$ & $\times A_{\mathrm{g}}, \mathrm{wl}$ & ere $f_{\mathrm{y}}$ is & the yield & stress ( & able.1) & $P_{\mathrm{u}}$ is the & ltimat & treng & & & & & \\
\hline
\end{tabular}


Table 4 Comparison of test result $\left(P_{\mathrm{u}}\right)$ with Design method $-\mathrm{kN}$

\begin{tabular}{|c|c|c|c|c|c|c|c|c|c|c|c|c|c|c|c|}
\hline \multirow{2}{*}{ Test } & \multirow{2}{*}{ Specimens } & \multicolumn{2}{|c|}{ Test result } & \multicolumn{2}{|c|}{ Elastic buckling load } & \multirow{2}{*}{$P_{l^{*}}$} & \multicolumn{3}{|c|}{ DSM-1 } & \multicolumn{3}{|c|}{ DSM-2 } & \multicolumn{3}{|c|}{ DSM-3 } \\
\hline & & $P_{\mathrm{u}}$ & Mode & $P_{\mathrm{crl}}$ & $P_{\text {crd }}$ & & $P_{\mathrm{D} 1}$ & Mode & $P_{\mathrm{D} 1} / P_{\mathrm{u}}$ & $P_{\mathrm{D} 2}$ & Mode & $P_{\mathrm{D} 2} / P_{\mathrm{u}}$ & $P_{\mathrm{D} 3}$ & Mode & $P_{\mathrm{D} 3} / P_{\mathrm{u}}$ \\
\hline \multirow{9}{*}{$\begin{array}{l}\infty \\
\stackrel{\infty}{\Xi} \\
\Xi \\
\tilde{z} \\
3\end{array}$} & SC-1 & 160 & LD & 153 & 187 & 202 & 164 & LG & 1.02 & 168 & D & 1.05 & 139 & LDG & 0.87 \\
\hline & SC-2 & 150 & LD & 153 & 187 & 202 & 164 & LG & 1.09 & 168 & $\mathrm{D}$ & 1.12 & 139 & LDG & 0.93 \\
\hline & SC-3 & 130 & LD & 153 & 187 & 202 & 164 & LG & 1.26 & 168 & $\mathrm{D}$ & 1.29 & 139 & LDG & 1.07 \\
\hline & MC-1 & 128 & LDG & 153 & 187 & 202 & 150 & LG & 1.18 & 168 & $\mathrm{D}$ & 1.31 & 131 & LDG & 1.02 \\
\hline & MC-2 & 125 & LDG & 153 & 187 & 202 & 150 & LG & 1.20 & 168 & $\mathrm{D}$ & 1.34 & 131 & LDG & 1.05 \\
\hline & MC-3 & 135 & LDG & 153 & 187 & 202 & 150 & LG & 1.11 & 168 & $\mathrm{D}$ & 1.24 & 131 & LDG & 0.97 \\
\hline & LC-1 & 89 & G & 153 & 187 & 202 & 89 & LG & 1.00 & 89 & LG & 1.00 & 84 & LG & 0.94 \\
\hline & LC-2 & 97 & G & 153 & 187 & 202 & 89 & LG & 0.92 & 89 & LG & 0.92 & 84 & LG & 0.86 \\
\hline & LC-3 & 81 & G & 153 & 187 & 202 & 89 & LG & 1.10 & 89 & LG & 1.10 & 84 & LG & 1.03 \\
\hline \multirow{22}{*}{ 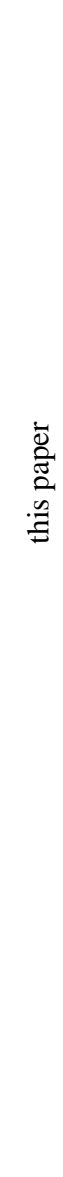 } & SC3-90-A1 & 127.7 & $\mathrm{~L}$ & 176 & 161 & 125 & 106 & LG & 0.83 & 117 & D & 0.92 & 117 & $\mathrm{D}$ & 0.92 \\
\hline & SC3-90-A2 & 132.8 & $\mathrm{~L}$ & 180 & 165 & 128 & 109 & LG & 0.82 & 120 & D & 0.90 & 120 & D & 0.90 \\
\hline & SC3-90-A3 & 131.6 & $\mathrm{~L}$ & 173 & 166 & 128 & 109 & LG & 0.83 & 121 & D & 0.92 & 121 & D & 0.92 \\
\hline & MC3-90-A1 & 88.8 & LDG & 181 & 164 & 125 & 82 & LG & 0.92 & 88 & LG & 0.99 & 88 & LG & 0.99 \\
\hline & MC3-90-A2 & 103 & LDG & 186 & 168 & 128 & 85 & LG & 0.83 & 91 & LG & 0.89 & 91 & LG & 0.89 \\
\hline & MC3-90-A3 & 97.7 & LDG & 176 & 162 & 125 & 82 & LG & 0.83 & 88 & LG & 0.90 & 88 & LG & 0.90 \\
\hline & LC3-90-A1 & 42.6 & G & 180 & 166 & 127 & 43 & LG & 1.00 & 41 & LG & 0.97 & 41 & LG & 0.97 \\
\hline & LC3-90-A2 & 39.9 & G & 180 & 165 & 124 & 40 & LG & 1.01 & 39 & LG & 0.98 & 39 & LG & 0.98 \\
\hline & LC3-90-A3 & 41.2 & G & 186 & 171 & 125 & 40 & $\mathrm{LG}$ & 0.98 & 39 & LG & 0.95 & 39 & LG & 0.95 \\
\hline & SC3-140-A2 & 130.6 & LD & 120 & 156 & 176 & 139 & LG & 1.07 & 145 & D & 1.11 & 119 & LDG & 0.91 \\
\hline & SC3-140-A2 & 139.6 & LD & 115 & 150 & 178 & 139 & LG & 0.99 & 143 & D & 1.03 & 118 & LDG & 0.84 \\
\hline & SC3-140-A3 & 138.8 & LD & 117 & 154 & 178 & 140 & LG & 1.01 & 145 & D & 1.04 & 119 & LDG & 0.86 \\
\hline & MC3-140-A1 & 124 & LDG & 118 & 159 & 179 & 103 & LG & 0.83 & 117 & LG & 0.94 & 95 & LDG & 0.76 \\
\hline & MC3-140-A2 & 101 & LDG & 117 & 157 & 176 & 100 & LG & 0.99 & 114 & LG & 1.13 & 93 & LDG & 0.92 \\
\hline & MC3-140-A3 & 105.8 & LDG & 119 & 156 & 176 & 101 & LG & 0.95 & 114 & LG & 1.08 & 93 & LDG & 0.88 \\
\hline & LC3-140-A1 & 49.2 & G & 110 & 157 & 174 & 51 & LG & 1.04 & 49 & LG & 0.99 & 49 & $\mathrm{~L}+\mathrm{G}$ & 0.99 \\
\hline & LC3-140-A2 & 46.9 & G & 113 & 148 & 174 & 51 & LG & 1.08 & 48 & LG & 1.02 & 48 & $\mathrm{~L}+\mathrm{G}$ & 1.02 \\
\hline & LC3-140-A3 & 50.2 & G & 119 & 166 & 179 & 52 & $\mathrm{LG}$ & 1.04 & 49 & LG & 0.98 & 49 & $\mathrm{~L}+\mathrm{G}$ & 0.98 \\
\hline & & & & & & & Mean & & 1.00 & & & 1.04 & & & 0.94 \\
\hline & & & & & & & $\mathrm{SD}$ & & 0.12 & & & 0.13 & & & 0.07 \\
\hline & & & & & & & MAX & & 1.26 & & & 1.34 & & & 1.07 \\
\hline & & & & & & & MIN & & 0.82 & & & 0.89 & & & 0.76 \\
\hline
\end{tabular}


Table 5 Nominal dimensions, material properties and test result of the test members of Wang [18].

\begin{tabular}{|c|c|c|c|c|c|c|c|}
\hline \multirow{2}{*}{ Specimens } & \multicolumn{5}{|c|}{ Nominal dimensions $(\mathrm{mm})$} & \multicolumn{2}{|c|}{ Test result } \\
\hline & $l$ & $h$ & $b$ & $d$ & $t$ & $P_{\mathrm{u}}(\mathrm{kN})$ & Failure Mode \\
\hline SC-1 & & & & & & 160 & LD \\
\hline $\mathrm{SC}-2$ & 450 & & & & & 150 & LD \\
\hline $\mathrm{SC}-3$ & & & & & & 130 & LD \\
\hline MC-1 & & & & & & 128 & LDG \\
\hline MC-2 & 1200 & 140 & 41 & 14 & 1.6 & 125 & LDG \\
\hline MC-3 & & & & & & 135 & LDG \\
\hline LC-1 & & & & & & 89 & G \\
\hline LC-2 & 3000 & & & & & 97 & G \\
\hline LC-3 & & & & & & 81 & G \\
\hline
\end{tabular}

Note: 1 . The yield stress $f_{\mathrm{y}}=334.04 \mathrm{Mpa}$;

2. The Elastic module $E=2.23 \times 10^{5} \mathrm{Mpa}$;

3. $l$ is the length of the column and $t$ is the thickness of the plate.

4. $h, b$ and $d$ are the width of web, flanges and lips, respectively.

Table 6 Comparison of test result $\left(P_{\mathrm{u}}\right)$ with DSM estimates $\left(P_{\mathrm{n}}\right)-\mathrm{kN}$.

\begin{tabular}{|c|c|c|c|c|c|c|c|c|c|c|c|c|c|c|c|}
\hline Specimens & Mode & $P_{\mathrm{u}}$ & $\lambda_{\mathrm{le}}$ & $P_{\text {nd }}$ & $P_{\text {nde }}$ & $P_{\text {nld }}$ & $P_{\text {nld* }}$ & $P_{\text {nlde }}$ & $P_{\text {nlde* }}$ & $P_{\mathrm{nd}} / P_{\mathrm{u}}$ & $P_{\text {nde }} / P_{\mathrm{u}}$ & $P_{\mathrm{nld}} / P_{\mathrm{u}}$ & $P_{\mathrm{nld} *} / P_{\mathrm{u}}$ & $P_{\text {nlde }} / P_{\mathrm{u}}$ & $P_{\text {nlde }} / P_{\mathrm{u}}$ \\
\hline $\mathrm{SC}-1$ & LD & 160.0 & 1.46 & 168 & 166 & 126 & 141 & 107 & 139 & 1.05 & 1.04 & 0.79 & 0.88 & 0.67 & 0.87 \\
\hline $\mathrm{SC}-2$ & LD & 150.0 & 1.46 & 168 & 166 & 126 & 141 & 107 & 139 & 1.12 & 1.10 & 0.84 & 0.94 & 0.71 & 0.93 \\
\hline $\mathrm{SC}-3$ & LD & 130.0 & 1.46 & 168 & 166 & 126 & 141 & 107 & 139 & 1.29 & 1.27 & 0.97 & 1.08 & 0.82 & 1.07 \\
\hline MC-1 & LDG & 128.0 & 1.37 & 168 & 154 & 126 & 141 & 103 & 131 & 1.31 & 1.20 & 0.99 & 1.1 & 0.8 & 1.02 \\
\hline MC-2 & LDG & 125.0 & 1.37 & 168 & 154 & 126 & 141 & 103 & 131 & 1.34 & 1.23 & 1.01 & 1.13 & 0.82 & 1.05 \\
\hline MC-3 & LDG & 135.0 & 1.37 & 168 & 154 & 126 & 141 & 103 & 131 & 1.24 & 1.14 & 0.93 & 1.04 & 0.76 & 0.97 \\
\hline MC3-90-A1 & LDG & 88.8 & 1.09 & 118 & 90 & 90 & 99 & 66 & 79 & 1.32 & 1.02 & 1.01 & 1.12 & 0.75 & 0.89 \\
\hline MC3-90-A2 & LDG & 103.0 & 1.08 & 121 & 94 & 93 & 102 & 69 & 82 & 1.17 & 0.91 & 0.9 & 0.99 & 0.67 & 0.80 \\
\hline MC3-90-A3 & LDG & 97.7 & 1.10 & 117 & 90 & 89 & 99 & 66 & 79 & 1.20 & 0.93 & 0.91 & 1.01 & 0.67 & 0.81 \\
\hline SC3-140-A2 & LD & 130.6 & 1.59 & 145 & 145 & 105 & 120 & 88 & 119 & 1.11 & 1.11 & 0.8 & 0.92 & 0.67 & 0.91 \\
\hline SC3-140-A2 & LD & 139.6 & 1.62 & 143 & 143 & 103 & 118 & 86 & 118 & 1.03 & 1.02 & 0.74 & 0.85 & 0.62 & 0.84 \\
\hline SC3-140-A3 & $\mathrm{LD}$ & 138.8 & 1.61 & 145 & 144 & 104 & 119 & 87 & 119 & 1.04 & 1.04 & 0.75 & 0.86 & 0.63 & 0.86 \\
\hline MC3-140-A1 & LDG & 124.0 & 1.25 & 147 & 111 & 106 & 122 & 76 & 95 & 1.19 & 0.89 & 0.85 & 0.98 & 0.61 & 0.76 \\
\hline MC3-140-A2 & LDG & 101.0 & 1.26 & 145 & 108 & 104 & 119 & 74 & 93 & 1.44 & 1.07 & 1.03 & 1.18 & 0.73 & 0.92 \\
\hline \multirow[t]{5}{*}{ MC3-140-A3 } & LDG & 105.8 & 1.24 & 145 & 108 & 104 & 120 & 75 & 93 & 1.37 & 1.02 & 0.99 & 1.13 & 0.71 & 0.88 \\
\hline & & & & & & & & Mean & & 1.21 & 1.07 & 0.90 & 1.01 & 0.71 & 0.91 \\
\hline & & & & & & & & SD & & 0.13 & 0.11 & 0.10 & 0.11 & 0.07 & 0.09 \\
\hline & & & & & & & & MAX & & 1.44 & 1.27 & 1.03 & 1.18 & 0.82 & 1.07 \\
\hline & & & & & & & & MIN & & 1.03 & 0.89 & 0.74 & 0.85 & 0.61 & 0.76 \\
\hline
\end{tabular}




\section{Figures}

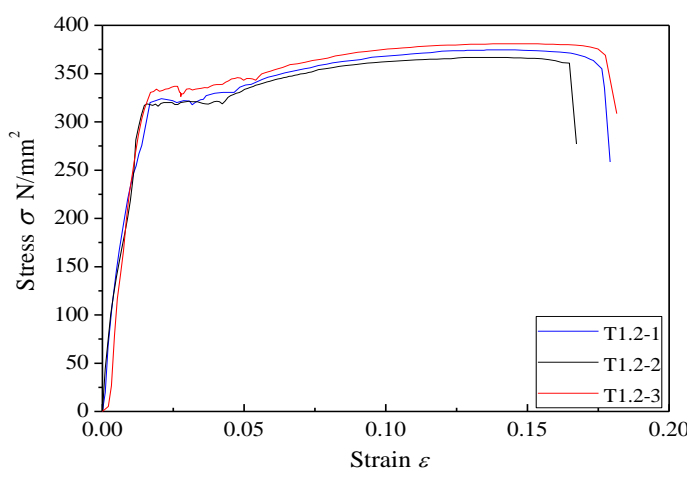

(a)

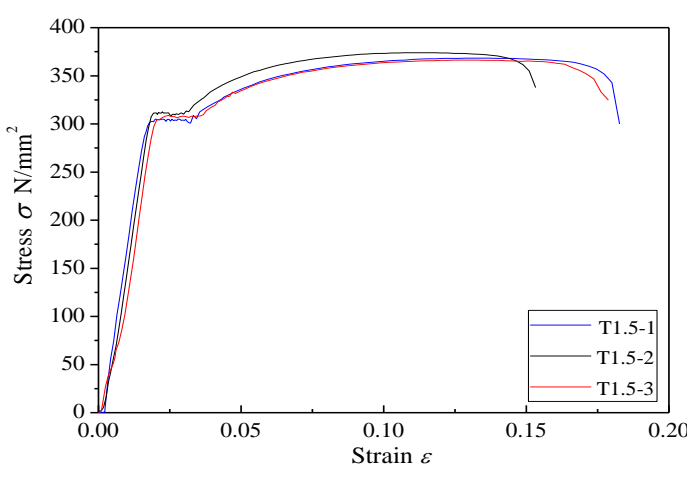

(b)

Fig.1 Stress vs. strain curve. (a) $t=1.2$. (b) $t=1.5$.

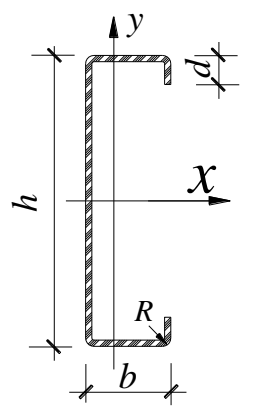

(a)

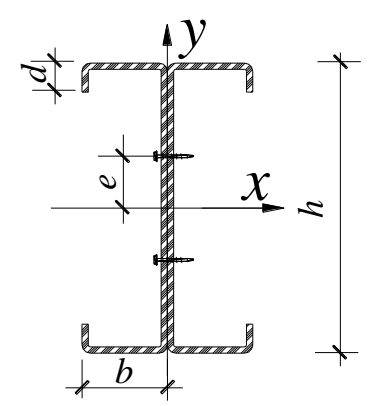

(b)

Fig. 2 Cross-section geometry specimen: (a) C-section. (b) Built-up I-section.

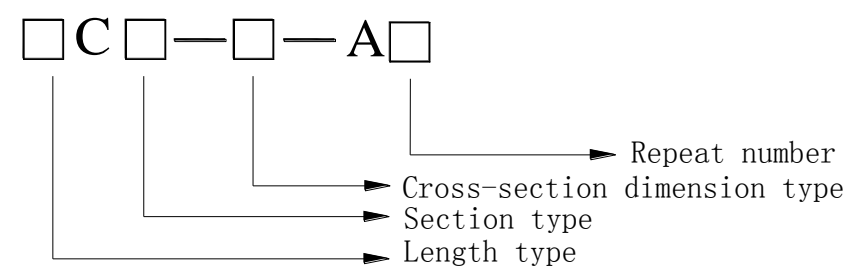

Fig.3. Labeling rule of specimens 


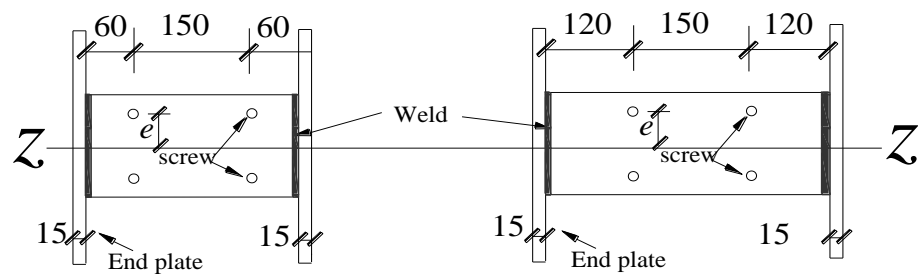

(a)

(b)

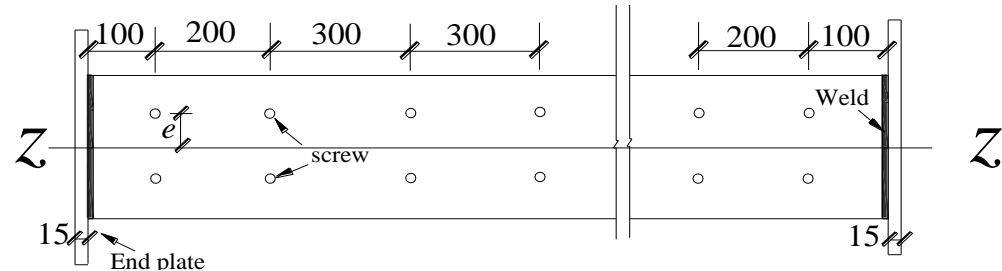

(c)

Fig.4 Arrangement of screw spacing: (a) SC3-90 type column. (b) SC3-140 type column. (c) MC3 and LC3 type column.

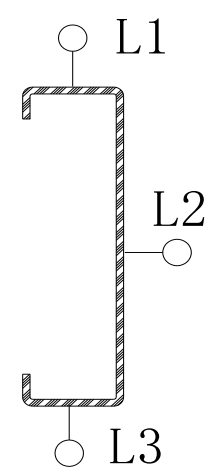

(a)

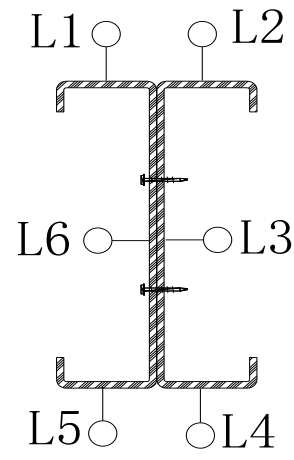

(b)

Fig. 5 Location of local geometric imperfection measurements: (a) C-section column. (b) Built-up I-section column.

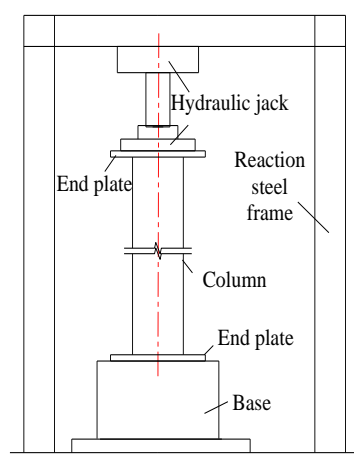

(a)

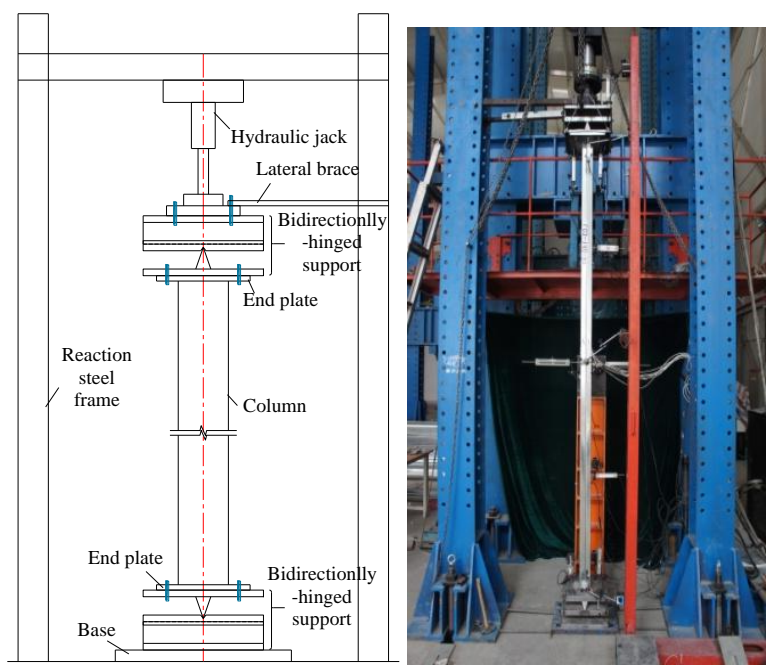

(b) 
Fig.6 Test set-up: (a) SC type specimens. (b) MC and LC type specimens.

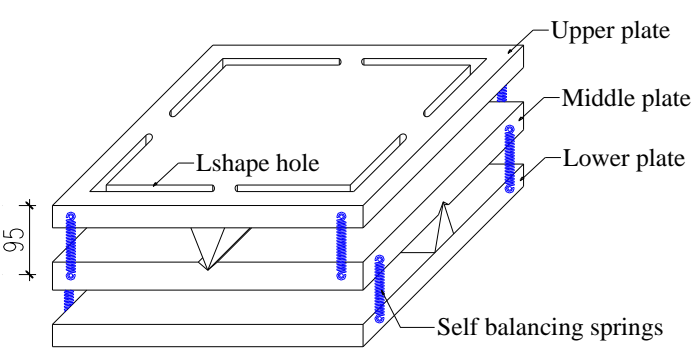

(a)

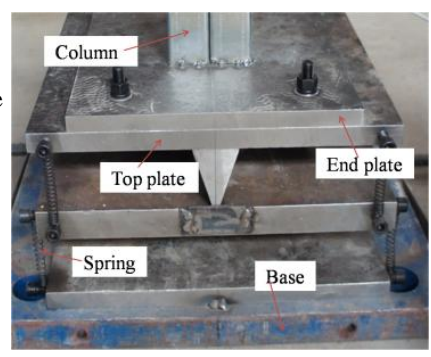

(b)

Fig.7 Bidirectional hinged support: (a) Configuration of the support device.

(b) Connections between the supported device and tested members

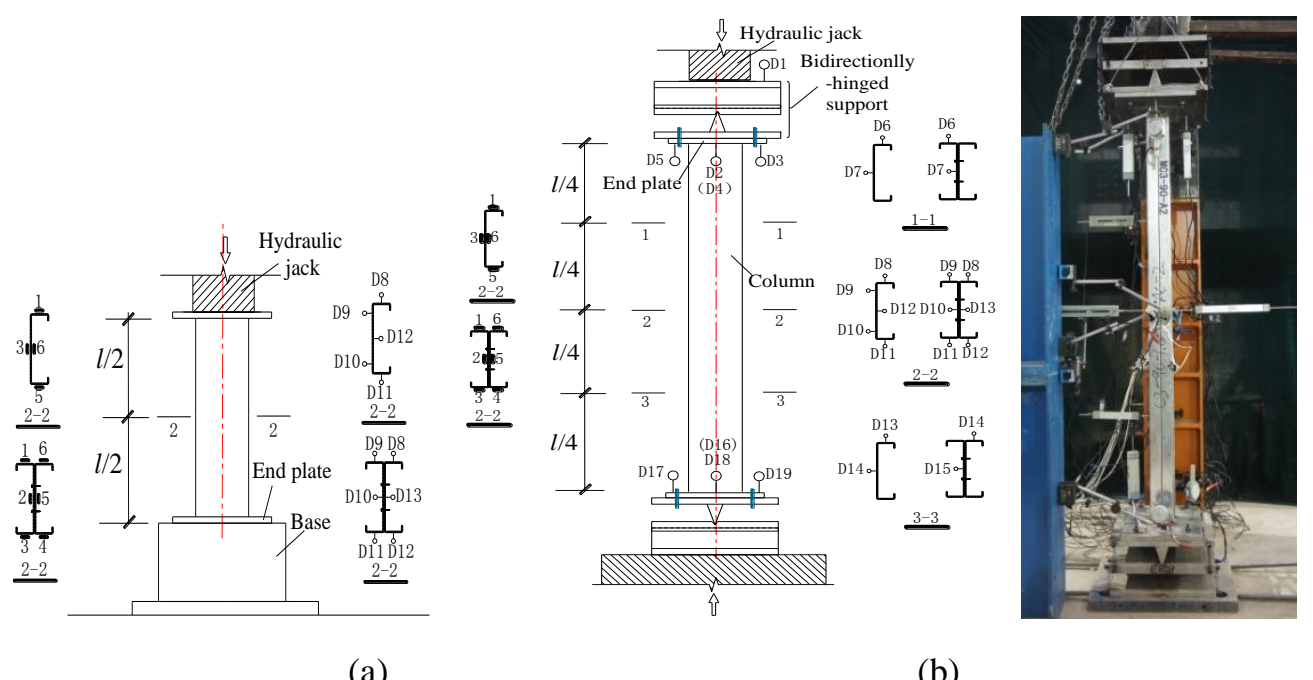

(a)

(b)

Fig.8 Arrangement of strain gauges and LVDTS: (a) SC type specimens.

(b) MC and LC type specimens.

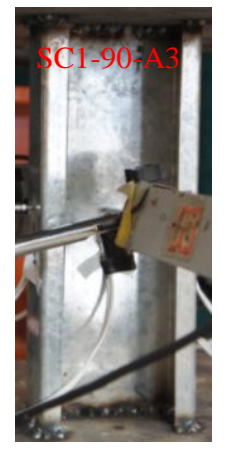

(a)

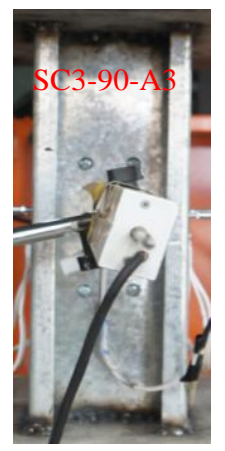

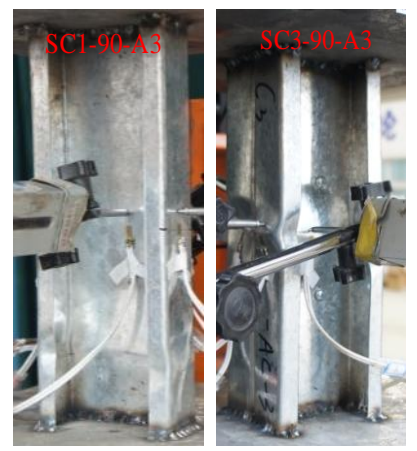

(b)
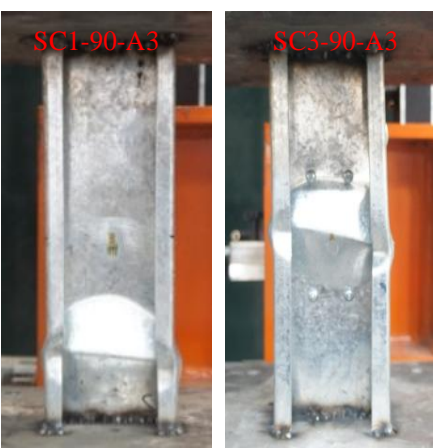

(c)

Fig.9 Comparison between the SC1-90-A3 and SC3-90-A3 specimens: (a) Local buckling occurred. (b) Right approaching the ultimate load. (c) Post-ultimate stage 


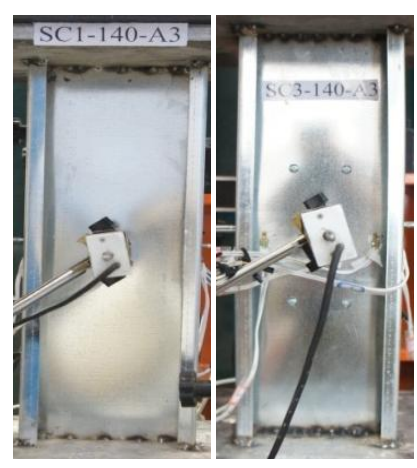

(a)

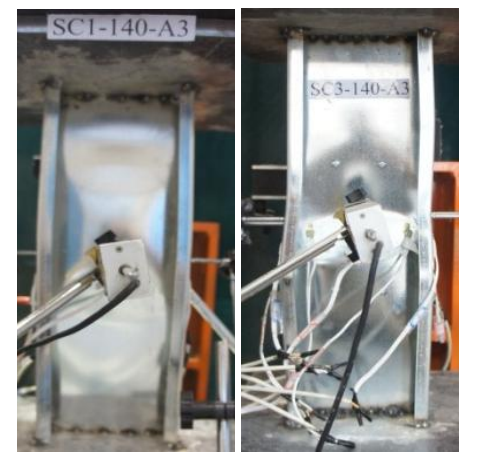

(b)
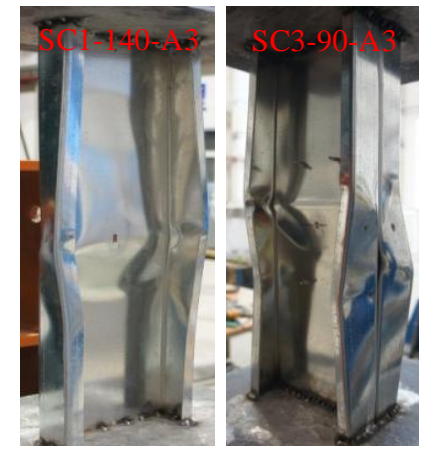

(c)

Fig.10 Comparison between the SC1-140-A3 and SC3-140-A3 specimens: (a) Local buckling occurred. (b) Interaction of local and distortional buckling occurred. (c) Post-ultimate stage

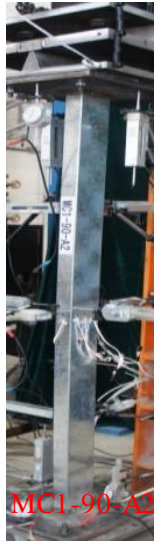

(a)

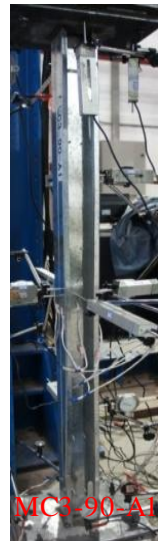

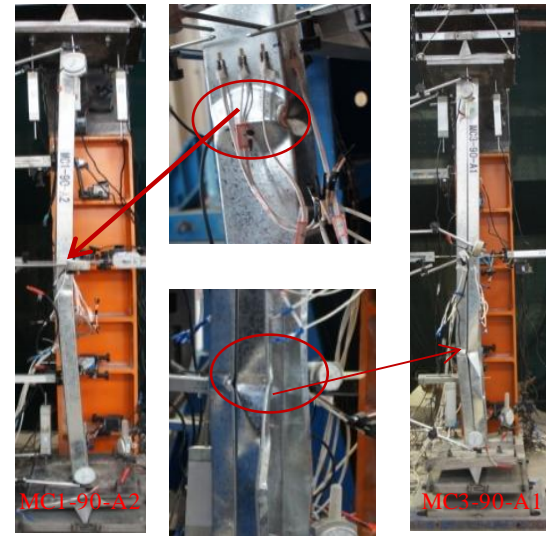

(b)

Fig.11 Comparison between the MC1-90-A2 and MC3-90-A1 specimens:

(a) local buckling occurred. (b) Right approaching the ultimate load.

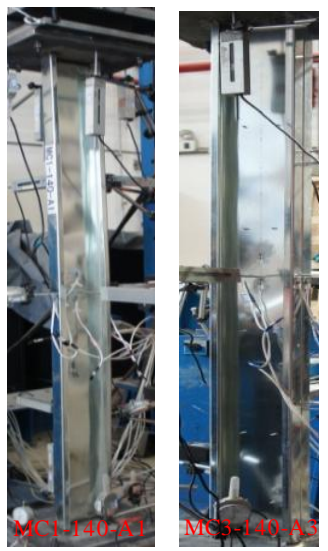

(a)
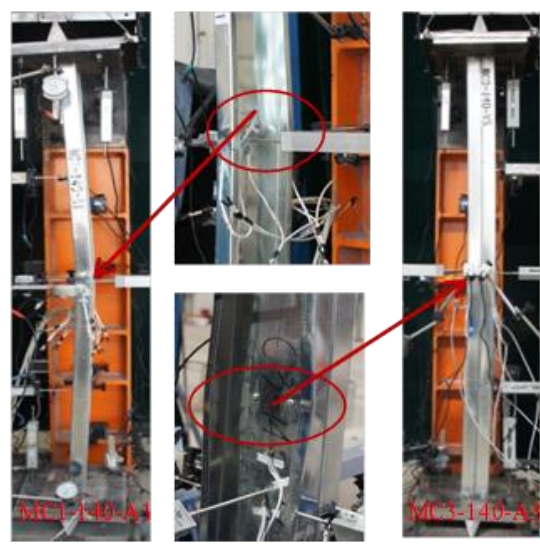

(b)

Fig.12 Comparison between the MC1-140-A1 and MC3-140-A3 specimens:

(a) Local buckling occurred. (b) Right approaching the ultimate load. 

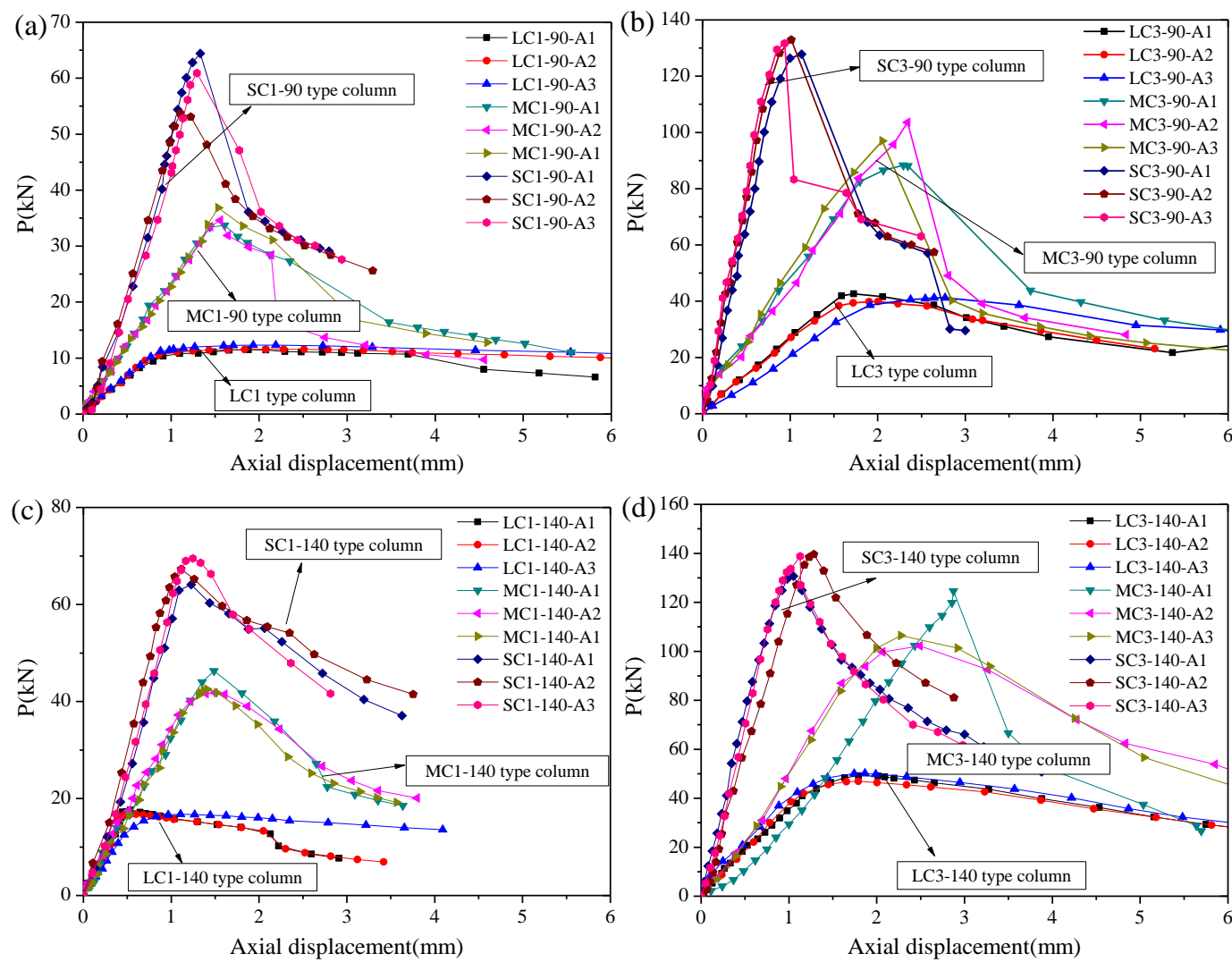

Fig. 13 Load vs. Axial displacement curves for the tested members: (a) C1-90 type C-section columns. (b) C3-90 type built-up columns (c) C1-140 type C-section columns. (d) C3-140 type built-up columns

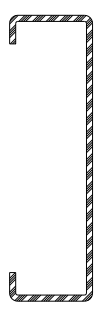

(a)

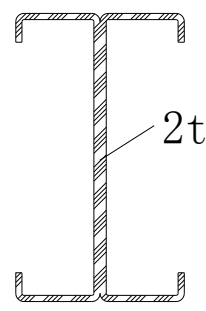

(b)

Fig. 14 Cross-section assumptions for the calculation of design strength of I-shaped sections: (a)

Local and distortional buckling load. (b) Overall buckling load.
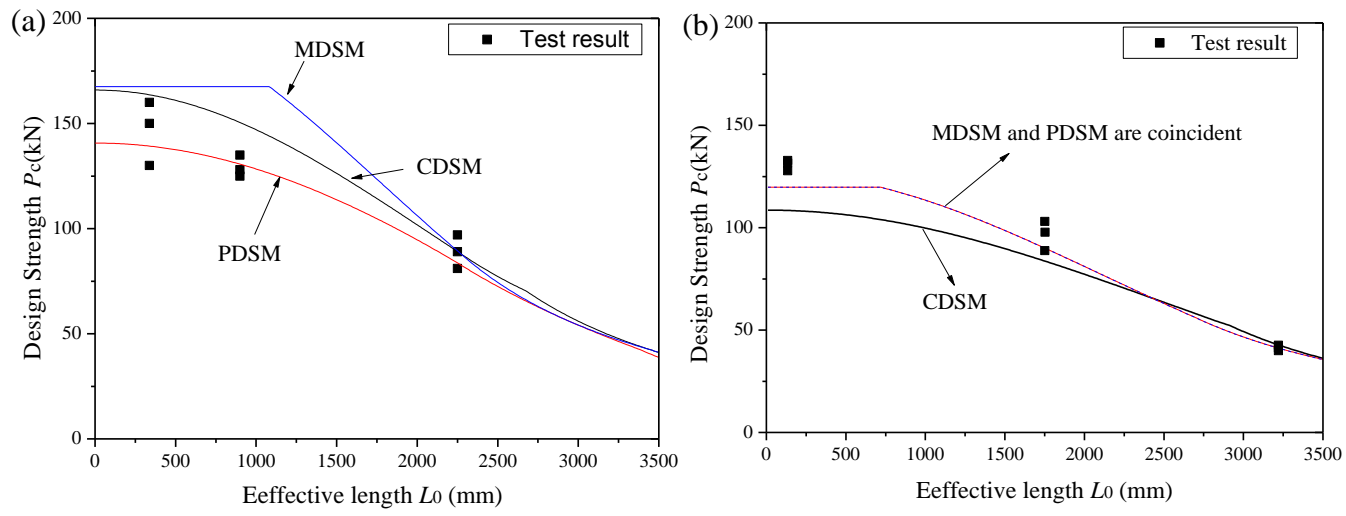


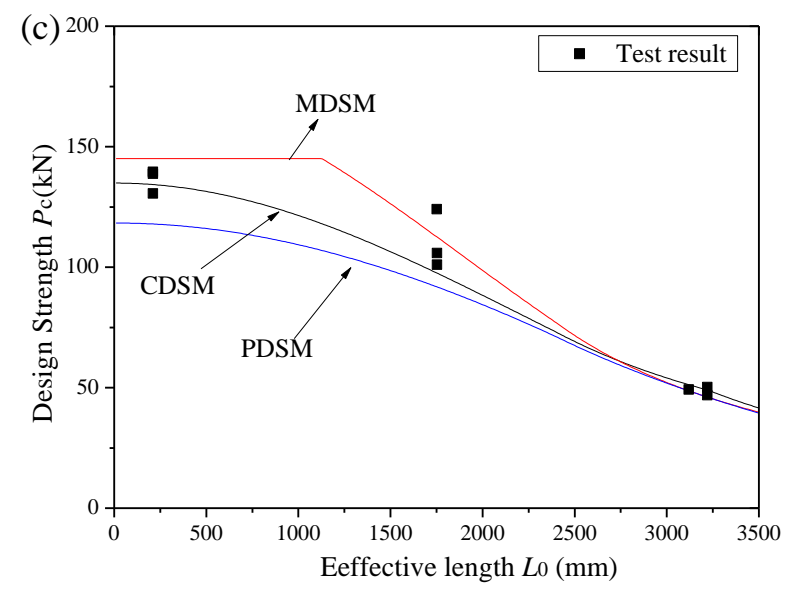

Fig. 15 Comparison of design method and the test result: (a) $\mathrm{C} 3$ type built-up column in [18]. (b) C3-90 type built-up column in this paper. (c) C3-140 type built-up column in this paper.

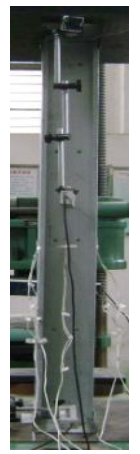

(a)

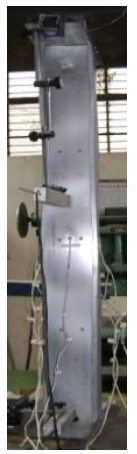

(b)

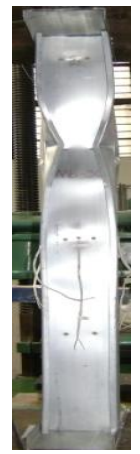

(c)

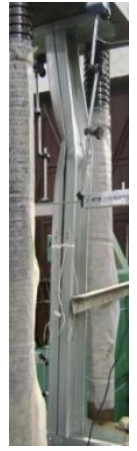

(d)

Fig.16 Deformation evolutions of MC-3 members in Ref. [18]: (a) Before testing. (b) Approaching the ultimate load (c) Front view at post-ultimate stage. (d) Side view at post-ultimate stage.
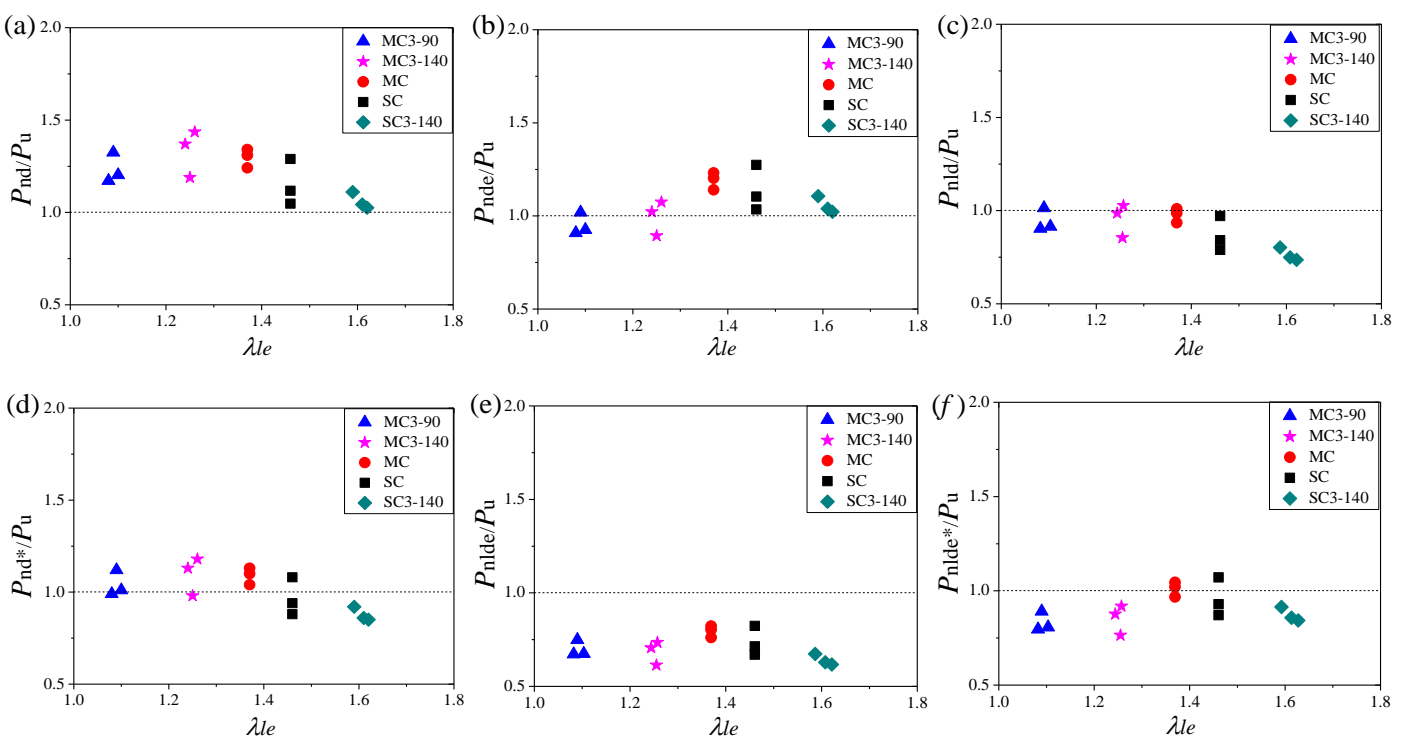

Fig.17 Comparisons between DSM estimates and test result for column failing in LD and LDG interactive mode: (a) $P_{\mathrm{nd}} / P_{\mathrm{n}}$ vs $\lambda_{\mathrm{le}}$, (b) $P_{\mathrm{nde}} / P_{\mathrm{n}}$ vs $\lambda_{\mathrm{le}}$, (c) $P_{\mathrm{nld}} / P_{\mathrm{n}}$ vs $\lambda_{\mathrm{le}}$, (d) $P_{\mathrm{nld}} * / P_{\mathrm{n}}$ vs $\lambda_{\mathrm{le}}$, (e) $P_{\mathrm{nlde}} / P_{\mathrm{n}}$ vs $\lambda_{\mathrm{le}}$, (f) $P_{\mathrm{nlde}} * / P_{\mathrm{n}}$ vs $\lambda_{\text {le }}$. 